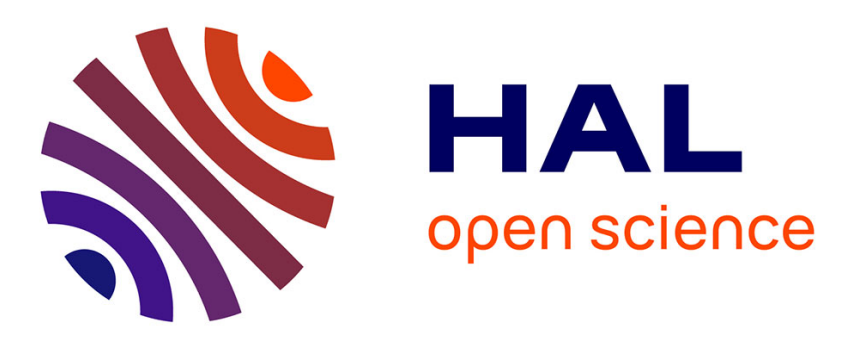

\title{
Finding Adapted Quinones for Harvesting Electrons from Photosynthetic Algae Suspensions
}

\author{
Adnan Sayegh, Luca A Perego, Marc Arderiu Romero, Louis Escudero,
} Jérôme Delacotte, Manon Guille-Collignon, Laurence Grimaud, Benjamin Bailleul, Frédéric Lemaître

\section{To cite this version:}

Adnan Sayegh, Luca A Perego, Marc Arderiu Romero, Louis Escudero, Jérôme Delacotte, et al.. Finding Adapted Quinones for Harvesting Electrons from Photosynthetic Algae Suspensions. ChemElectroChem, 2021, 8 (15), pp.2968-2978. 10.1002/celc.202100757 . hal-03359651

\section{HAL Id: hal-03359651 https: / hal.sorbonne-universite.fr/hal-03359651}

Submitted on 30 Sep 2021

HAL is a multi-disciplinary open access archive for the deposit and dissemination of scientific research documents, whether they are published or not. The documents may come from teaching and research institutions in France or abroad, or from public or private research centers.
L'archive ouverte pluridisciplinaire HAL, est destinée au dépôt et à la diffusion de documents scientifiques de niveau recherche, publiés ou non, émanant des établissements d'enseignement et de recherche français ou étrangers, des laboratoires publics ou privés. 


\section{Finding Adapted Quinones for Harvesting Electrons}

\section{from Photosynthetic Algae Suspensions}

Dr. Adnan Sayegh, ${ }^{\mathrm{a}}$ Dr. Luca A. Perego, ${ }^{\mathrm{b}}$ Marc Arderiu Romero, ${ }^{\mathrm{a}, \mathrm{c}}$ Louis Escudero, ${ }^{\mathrm{a}}$ Dr. Jérôme Delacotte, ${ }^{\mathrm{a}}$ Dr. Manon Guille-Collignon, ${ }^{\mathrm{a}}$ Dr. Laurence Grimaud, ${ }^{\mathrm{b}}$ Dr. Benjamin Bailleul, ${ }^{\mathrm{c}}$ Prof. Frédéric Lemaître ${ }^{\mathrm{a} *}$

a) PASTEUR, Département de Chimie, Ecole Normale Supérieure, PSL University, Sorbonne Université, CNRS, 75005 Paris, France.

b) Laboratoire des biomolécules (LBM), Département de chimie, Sorbonne Université, École normale supérieure, PSL University, Sorbonne Université, CNRS, 75005 Paris, France

c) Laboratory of Membrane and Molecular Physiology at IBPC, UMR 7141, CNRS/Sorbonne Université, 13 rue Pierre et Marie Curie, 75005 Paris, France

* Corresponding author: frederic.lemaitre@ sorbonne-universite.fr

Number of figures: 7

Number of tables: 2 

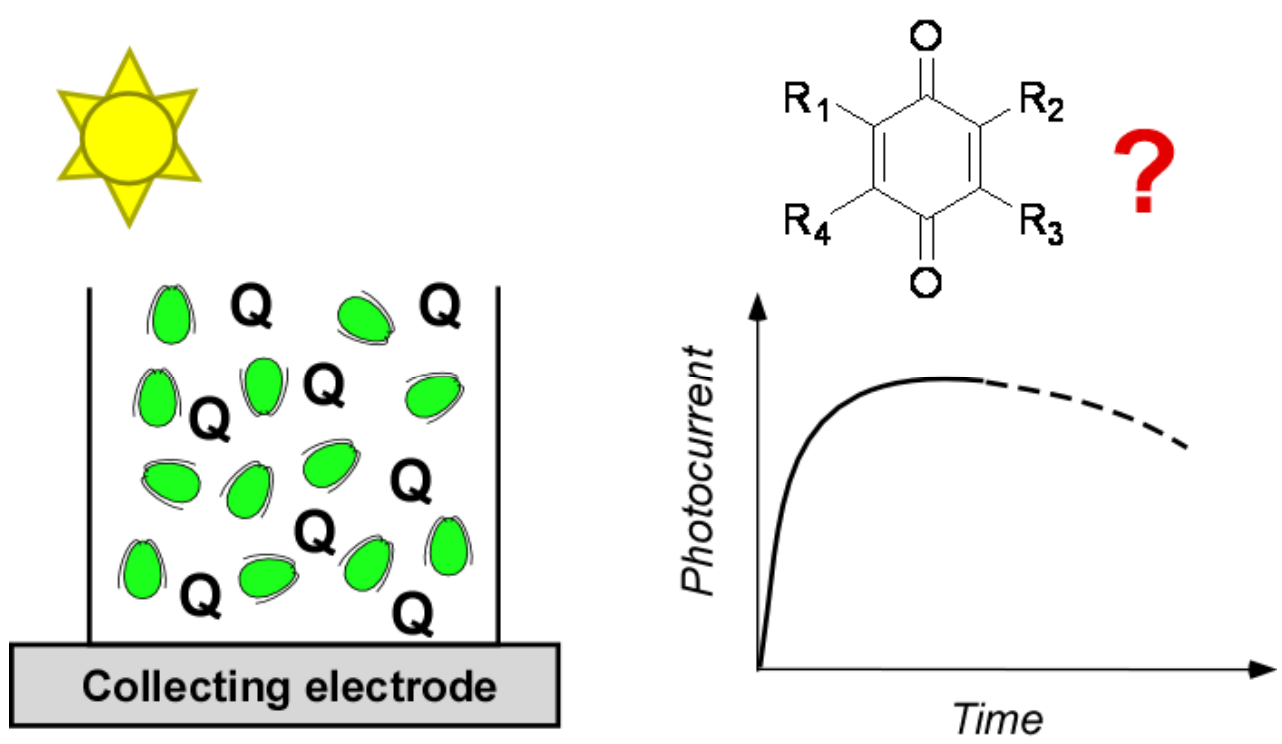

Performances of different quinones as redox mediators were investigated from suspensions of photosynthetic microalgae to produce photocurrents by using a miniaturized well-type $\mathrm{Au} / \mathrm{ITO}$ electrochemical device. Some electrochemical aspects were considered (maximum photocurrent, stability) but side-effects of quinones were also studied (cytotoxic concentration, ATPsynthase). Correlations with redox potentials gave a first view to find the best compromise between bioelectricity production and toxicity. 


\begin{abstract}
Among all the chemical and biotechnological strategies implemented to extract energy from oxygenic photosynthesis, several concern the use of intact photosynthetic organisms (algae, cyanobacteria...). This means rerouting (fully or partially) the electron flow from the photosynthetic chain to an outer collecting electrode generating thus a photocurrent. While diverting photosynthetic electrons from living biological systems is an encouraging approach, this strategy is limited by the need to use an electron shuttle. Redox mediators that are able to interact with an embedded photosynthetic chain are rather scarce. In this respect, exogenous quinones are the most frequently used. Unfortunately, some of them also act as poisoning agents within relatively long timeframes. It thus raises the question of the best quinone. In this work, we use a previously reported electrochemical device to analyze the performances of different quinones. Photocurrents (maximum photocurrent, stability) were measured from suspensions of Chlamydomonas reinhardtii algae/quinones by chronoamperometry and compared to parameters like quinone redox potentials or cytotoxic concentration. From these results, several quinones were synthesized and analyzed in order to find the best compromise between bioelectricity production and toxicity.
\end{abstract}

Keywords: photosynthesis; quinones; electrochemistry; Chlamydomonas reinhardtii algae; photocurrent 


\section{Introduction}

Photosynthesis is the fascinating process used by Nature to convert light into chemical energy. Mainly involved in plants and other organisms like algae and cyanobacteria, oxygenic photosynthesis relies on light absorption by chlorophyll antennae and photochemistry in reaction centers that triggers electron transfers along the photosynthetic chain (Figure 1A). It formally corresponds to a charge separation whose positive side induces the $\mathrm{H}_{2} \mathrm{O}$ oxidation and the negative side eventually leads to the $\mathrm{CO}_{2}$ reduction. This light-induced electron flow is obviously an inspiring mechanism in the current context of renewable energies and several strategies were recently considered to use photosynthesis as a light converter to electricity. This raises the question on how taking benefit from photosynthesis. ${ }^{[1]}$ On the one hand, only the principle of the photosynthetic process (i.e. a charge separation induced by light illumination) can be retained. This is the scope of photovoltaics and artificial photosynthesis. On the other hand, natural photosynthesis (i.e. by using the already existing photosynthetic chain) can be directly used as an already available light converter. The first field has led to the best performances so far although the other one is a more recent and growing field. ${ }^{[2]}$

It is quite difficult to classify all the photobioelectrochemical systems using natural photosynthesis. The main strategies were reported in some excellent reviews ${ }^{[3]}$ and especially very recent ones. ${ }^{[4]}$ What the strategies have in common is to involve an outer collecting electrode to reroute the electrons resulting from the light excitation of the photosynthetic machinery. Advantages can be taken from fragments of the photosynthetic organisms like isolated photosystems (PSII and PSI; often designated as semi-artificial photosynthesis) or thylakoid membranes in a manner to favor the electron transfer with the electrode. ${ }^{[5]}$ However, in the last decades, the use of intact photosynthetic organisms as "catalysts" was also considered due to the absence of extracting procedure and ability to be cultured. This corresponds to a broad field that is often termed as photosynthetic microbial fuel cells (PMFCs). Among them, those relying on a current production from water splitting reaction correspond to a promising subcategory named biophotovoltaics. ${ }^{[3 \mathrm{~g}, 4 \mathrm{a}]}$ Direct electron transfer can occur between the photosynthetic organism and the electrode but electron shuttles (soluble mediators like quinones, $\mathrm{Fe}(\mathrm{CN})_{6}{ }^{3-}$, phenazines or redox polymers...) also achieve mediated electron transfers that facilitate the exchanges between the collecting electrode and the biological target. ${ }^{[2 \mathrm{~b}, 6]}$

In this context, we recently focused on a strategy devoted to the use of an algae suspension mixed with soluble redox mediators. Due to their PSII acceptor ability, ${ }^{[7]}$ quinones 
are ideal candidates for this purpose. ${ }^{[6 a, 8]}$ In the past few years, we have indeed investigated the ability of several exogenous quinones to be reduced by a Chlamydomonas reinhardtii algae suspension. ${ }^{[9]}$ Based on these results, photocurrents $\left(\sim 60 \mu \mathrm{A} \mathrm{cm}^{-2}\right)$ were recorded by implementing a corresponding spectroelectrochemical set-up involving a polarized carbon gauze electrode (surface area $\sim \mathrm{cm}^{2}$ ). ${ }^{[10]}$ The current shape was globally consistent with the two expected complementary pathways (quinone (Q) reduction by illuminated algae and hydroquinone $\left(\mathrm{QH}_{2}\right)$ oxidation at the electrode surface; Figure 1B). Nevertheless, detailed modelings suggested deleterious side effects of quinones during the electron harvesting. ${ }^{[1]}$ This poisoning behaviour was investigated by means of chronoamperometry and fluorescence measurements. The oxidizing power of the given quinones was supposed to be crucial but relatively few quinones were investigated. ${ }^{[12]}$ All in all, these works pave the way for finding the best quinone in terms of chemical structure. However, although suitable for a preparative scale, the electrochemical set-up described above was not really adapted for systematic analyses of experimental parameters due to relatively long equilibration times before the experiment. This issue can be circumvented by using a miniaturized well-type Au/ITO electrochemical device. ${ }^{[13]}$ In this work, such a gold electrochemical device is used to analyze the performances of different quinones as redox mediators in the context of photosynthetic electron diverting from Chlamydomonas reinhardtii cells. Effects of quinone incubation on the algae proliferation were also investigated by using other approaches. All together, these results gave an overview of the properties requested by the ideal quinones (redox potential, concentration...). Several quinones were therefore synthesized and their ability to produce the best current (magnitude and stability) was evaluated.

\section{Experimental}

\subsection{Cell culture and preparation}

Two types of Chlamydomonas reinhardtii algae (wild-type or photosynthetic mutant) were used in this work. The wild type strain (hereafter referred as WT) derived from the 137c strain. ${ }^{[14]}$ The $\Delta p e t A$ mutant lacks cytochrome $\mathrm{b}_{6} f$ that corresponds to the impairment of the photosynthetic chain. ${ }^{[15]}$ In the absence of cytochrome $b_{6} f$ (the quinol:plastocyanin oxidoreductase), the plastoquinol generated by light-induced turnovers of Photosystem II cannot be reoxidized by photosystem I. It therefore leads to the fast interruption of lightdriven electron flow. In short, WT and $\Delta$ petA were grown in Tris Acetate Phosphate aqueous medium $\left(\mathrm{TAP}=\right.$ Tris base $\left(20 \mathrm{mmol} \mathrm{L}^{-1}\right), \mathrm{NH}_{4} \mathrm{Cl}\left(7 \mathrm{mmol} \mathrm{L} \mathrm{L}^{-1}\right), \mathrm{MgSO}_{4}\left(0.83 \mathrm{mmol} \mathrm{L}^{-1}\right)$, 
$\mathrm{CaCl}_{2}\left(0.45 \mathrm{mmol} \mathrm{L}^{-1}\right), \mathrm{K}_{2} \mathrm{HPO}_{4}\left(1.65 \mathrm{mmol} \mathrm{L}^{-1}\right), \mathrm{KH}_{2} \mathrm{PO}_{4}\left(1.05 \mathrm{mmol} \mathrm{L}{ }^{-1}\right), \mathrm{CH}_{3} \mathrm{CO}_{2} \mathrm{H}(0.3$ mmol $\left.\mathrm{L}^{-1}\right)$ ) at $25^{\circ} \mathrm{C}$ under rather dim light conditions $\left(50 \mu \mathrm{E} \mathrm{m}^{-2} \mathrm{~s}^{-1}\right)$ prior to further measurements. From a cell suspension at $2 \times 10^{6}$ cells $\mathrm{mL}^{-1}$, algae are resuspended (after centrifugation at $4000 \mathrm{~g}$ ) into Tris-minimal medium (= TAP without acetate) for further electrochemical or fluorescence experiments (final concentration of $2 \times 10^{7}$ cells mL ${ }^{-1}$ ). ${ }^{[9 b, 13]}$

\subsection{Chemical materials and solutions preparation}

All chemicals (including quinones or hydroquinones) have been purchased from SigmaAldrich and have been used without further purification. Practically, quinones or hydroquinones were dissolved in absolute ethanol to make fresh mother solutions $(10 \mathrm{mmol}$ $\left.\mathrm{L}^{-1}\right)$. Appropriate volumes of these solutions were thus directly added to the algae suspension (see text) for subsequent electrochemical (a well containing the cells; V $=500 \mu \mathrm{L}$ ) or fluorescence (a cuvette containing the algae suspension; $\mathrm{V}=2 \mathrm{~mL}$ ) experiments.

\subsection{Electrochemical experiments - Photocurrent recording}

The ITO/Au electrochemical device for measuring photocurrents from a quinone-algae mixture was described elsewhere. ${ }^{[13]}$ Briefly, a thin indium tin oxide (ITO) film (thickness $10 \mathrm{~nm}$ ) followed by another film of gold $(50 \mathrm{~nm})$ are sputtered onto a glass slide (Deckglaser Menzel-Glaser microscope cover slides, Fisher Scientific; 24 mm x 48 mm x $170 \mu \mathrm{m})$. A well $(9 \mathrm{~mm}$ diameter; volume $\sim 500 \mu \mathrm{L})$ is delimited on the ITO/Au modified glass slide by using PDMS (polydimethyloxane RTV-615; Momentive Performance Materials France). Electrical connections were made by using a copper wire and a silver paint (Radiospares) covered by insulating glue. Platinum wire $(30 \times 1 \mathrm{~mm})$ and $\mathrm{Ag} / \mathrm{AgCl}$ (35 x $0.5 \mathrm{~mm}$ ) wires were used as counter and reference (chloride anions $\sim 7.9 \mathrm{mmol} \mathrm{L}^{-1}$; see above) electrodes, respectively.

Chronoamperometry experiments were carried out with aqueous solutions (well of $\mathrm{V}=$ $500 \mu \mathrm{L}$ ) containing quinones/algae mixtures in Tris-minimal medium within the PDMS well using a Parstat 2273 potentiostat (Princeton Applied Research). Appropriate volumes of quinones in absolute ethanol were added to the algae suspension and kept 5 seconds at open circuit voltage (OCV) for equilibration. Then the working electrode was polarized at $0.38 \mathrm{~V}$ vs $\mathrm{Ag} / \mathrm{AgCl}$. After stabilization of the baseline ("dark current"), the light source shutter was opened (actinic white light from a Scott KL1500 LCD halogen lamp at P $=60 \mathrm{~mW} \mathrm{~cm} \mathrm{~cm}^{-2}$ ). 
The corresponding faradic photocurrent is then instantly measured. Light is turned off before the end of the experiment to allow the current to reach the baseline back. All plots and statistical analyses (average values \pm s.e.m.) were performed using SIGMA Plot 10.0 software (Systat Software Inc., Richmond, CA, USA).

\subsection{Spectroscopy measurements}

\subsubsection{Fluorescence experiments}

The fluorescence measurements were carried out according the procedure described in previous works. ${ }^{[9-10,12]}$ Briefly, fluorescence is measured by using a JTS-10 spectrophotometer (Biologic, Grenoble, France); an actinic red light $\left(\lambda=640 \mathrm{~nm} ; \mathrm{I}=135 \mu \mathrm{E} \mathrm{m}^{-2} \mathrm{~s}^{-1}\right)$ is first applied during few seconds to induce photosynthesis. The steady state fluorescence under that illumination is called Fs. A short subsequent supersaturating pulse $(250 \mathrm{~ms} ; \lambda=640 \mathrm{~nm}$; $\mathrm{I}=$ $5000 \mu \mathrm{E} \mathrm{m}^{-2} \mathrm{~s}^{-1}$ ) of exciting light is then applied to promote the full reduction of the quinone primary electro-acceptor $\mathrm{Q}_{\mathrm{A}}$ to $\mathrm{Q}_{\mathrm{A}}{ }^{-}$. The corresponding maximum fluorescence level $\left(\mathrm{F}_{\mathrm{M}}\right)$ allows one to calculate the quantum yield of PSII chemistry as $\Phi_{\mathrm{PSII}}=\left(\mathrm{F}_{\mathrm{M}}-\mathrm{Fs}\right) / \mathrm{F}_{\mathrm{M}}$. Incubation periods were achieved under dark conditions and gentle stirring in order to avoid aggregation either in presence of quinones or in absence of quinones as a control experiment. Fluorescence measurements have been performed every hour for each sample ( $\mathrm{V}=2 \mathrm{~mL})$. Each experiment was repeated three times.

\subsubsection{ATP synthase}

The saturated light flash (6 ns) was provided by a laser dye (LDS 698) pumped by an NDYAG second harmonic laser (Minilite Continuum). The interference filters at $520 \pm 6 \mathrm{~nm}$ and $546 \pm 6 \mathrm{~nm}$ have been used to measure absorption changes at desirable wavelengths. Cut-off filters (BG-39, Schott, Germany) was put in front of the measure and reference photodiodes to stop the actinic illumination. Electrochromic-Shift (ECS) measurements were calculated as the difference between the absorption changes at 520 and 546, to eliminate the contributions of the redox changes of the cytochrome $f$ and flat contributions due to diffusion. Before the saturating laser flash was applied, cells were dark adapted for 1 min. The kinetics of ECS changes after a single turnover laser flash consisted in 3 phases. The first experimental point after the flash (300 $\mu \mathrm{s}$, "a phase") corresponds to the electric field generated by 
photochemical events in the two photosystems. A second phase ( 10-20 ms, called "b phase") followed, reflecting the activity of the cytochrome $\mathrm{b}_{6} f$. The ECS decay (sometimes called "c phase") following the $a$ and $b$ phases reflects the consumption of the protons accumulated in the lumen by the activity of the CF1FO ATPase (Figure 5A).

\subsection{Synthesis of quinones}

Three quinones used in this work were not purchased but synthesized according to the following procedures.

\subsubsection{2,5-Dichloro-3,6-dimorpholino-1,4-benzoquinone $(\text { DCMorBQ })^{[16]}$}

A $50 \mathrm{~mL}$ round-bottom flask equipped with a magnetic stirrer was charged with a solution of chloranil $(246 \mathrm{mg}, 1.0 \mathrm{mmol})$ in 1,4-dioxane $(10 \mathrm{~mL})$. Morpholine $(0.50 \mathrm{~mL}, 500$ mg, 5.7 equiv) was then added. The reaction took place very quickly with a color change from yellow to yellow-brown. After stirring for 10 minutes at room temperature, methanol $(10 \mathrm{~mL})$ and water $(1 \mathrm{~mL})$ were added. After ageing in the mother liquor for 15 minutes, the precipitated solid was filtered and dried in vacuo. The title compound was thus obtained in the form of a brown solid (253 mg, 73\% yield). ${ }^{1} \mathrm{H}$ NMR (300 MHz, $\left.\mathrm{CDCl}_{3}\right): \delta=3.90-3.70$ (m, 8H), 3.70-3.48 (m, 8H) ppm; ${ }^{13} \mathrm{C}$ NMR (75 MHz, $\left.\mathrm{CDCl}_{3}\right): \delta=176.1,148.1,116.4,67.7,52.2$ ppm.

\subsubsection{2,5-Dichloro-3,6-di-tert-butylthio-1,4-benzoquinone $(D C T h i o B Q)^{[17]}$}

A $50 \mathrm{~mL}$ round-bottom flask equipped with a magnetic stirrer was charged with chloranil (683 mg, $2.8 \mathrm{mmol})$, dichloromethane $(12 \mathrm{~mL})$, ethanol (12 mL), sodium 2-methyl2-propanethiolate (690 mg, $6.2 \mathrm{mmol}, 2.2$ equiv), and acetic acid (480 $\mu \mathrm{L}, 8.4 \mathrm{mmol}, 3.0$ equiv). The resulting mixture was stirred overnight at room temperature, then diluted with dichloromethane $(50 \mathrm{~mL})$ and extracted with water $(2 \times 25 \mathrm{~mL})$. The organic layer was dried over $\mathrm{MgSO}_{4}$ and concentrated under reduced pressure. The title compound was thus obtained in the form of a dark brown solid (590 mg, 60\% yield). ${ }^{1} \mathrm{H}$ NMR (300 MHz, $\left.\mathrm{CDCl}_{3}\right): \delta=1.44$ (s, 18H) ppm; ${ }^{13} \mathrm{C} \mathrm{NMR}\left(75 \mathrm{MHz}, \mathrm{CDCl}_{3}\right): \delta=173.9,151.4,141.5,53.5,32.6 \mathrm{ppm}$.

\subsubsection{2,3-Dimethyl-5-phenyl-1,4-benzoquinone $(D M P P B Q)^{[18]}$}

A pressure-resistant tube $(25 \mathrm{~mL}$ capacity, calculated reaction pressure: 5 bar, maximum allowed pressure: 20 bar) equipped with a magnetic stirrer was charged with 2,3- 
dimethylbenzoquinone (138.1 $\mathrm{mg}, \quad 1.0 \mathrm{mmol})$, benzene $(6.0 \mathrm{~mL})$, palladium(II) acetylacetonate (15.2 mg, $0.050 \mathrm{mmol}, 0.050$ equiv), $\mathrm{Ag}_{2} \mathrm{CO}_{3}$ (827.5 mg. $3.0 \mathrm{mmol}, 3.0$ equiv), DMSO (0.25 mL, $3.50 \mathrm{mmol}, 3.50$ equiv), and pivalic acid (205.0 mg, $2.0 \mathrm{mmol}, 2.0$ equiv). The tube was sealed and the resulting mixture was stirred at $140{ }^{\circ} \mathrm{C}$ overnight. The reaction mixture was cooled to room temperature, transferred to a round-bottom flask and concentrated under reduced pressure. The residue was purified by flash chromatography on silica gel (eluent: toluene) to give the title compound in the form of yellow crystals (118.5 $\mathrm{mg}, 56 \%$ yield). ${ }^{1} \mathrm{H}$ NMR (300 MHz, $\left.\mathrm{CDCl}_{3}\right): \delta=7.50-7.40(\mathrm{~m}, 5 \mathrm{H}), 6.81(\mathrm{~s}, 1 \mathrm{H}), 2.11(\mathrm{~s}$, $3 \mathrm{H}), 2.08(\mathrm{~s}, 3 \mathrm{H}) \mathrm{ppm} ;{ }^{13} \mathrm{C} \mathrm{NMR}\left(75 \mathrm{MHz}, \mathrm{CDCl}_{3}\right): \delta=187.7,186.9,145.9,141.4,140.9$, $133.4,132.6,129.9,129.4,128.5,12.9,12.3 \mathrm{ppm}$.

\subsection{Threshold concentration of quinones for cell division}

Suspended algae in Tris-minimal medium $\left(2 \times 10^{7}\right.$ cells $\left.\mathrm{mL}^{-1}\right)$ are stirred under dim light $\left(50 \mu \mathrm{E} \mathrm{m}^{-2} \mathrm{~s}^{-1}\right)$ in presence of exogenous quinones (from 10 to $100 \mu \mathrm{mol} \mathrm{L}{ }^{-1}$ ) over one hour. The suspension is then diluted in fresh TAP medium. Every $24 \mathrm{~h}$, the algae concentration in both samples is measured (Malassez cell counting). The results are compared to a control experiment without adding quinones. In such a case, counting the cells every $24 \mathrm{~h}$ helps to determine the growing rate (defined as the increase in cell concentration every $24 \mathrm{~h}$ ) as a function of time. The corresponding exponential increase of the growing rate allows one to extract a rate constant equal to $0.134 \mathrm{~h}^{-1}$ i.e. a doubling time of $5.2 \mathrm{~h}$. Such a reference value allows one to extract the fraction of cells able to grow after being incubated with exogenous quinones.

\section{Results and discussion}

\subsection{Photocurrents resulting from algae-quinones mixtures}

Chronoamperometry measurements were performed using the well-shaped device reported in a previous work. ${ }^{[13]}$ Photocurrents from Chlamydomonas reinhardtii algae suspension with several quinones (see Figure 2A) could therefore be recorded. A representative chronoamperogram (2,6-DCBQ / WT) is displayed in Figure 2B. Under illumination, the exogenous quinones interact with the photosynthetic chain within the algae suspension. This leads to the reduction of quinones (Q) and the subsequent formation of hydroquinones $\left(\mathrm{QH}_{2}\right)$ that are then oxidized at the gold electrode surface. Through this electrocatalysis pathway, the resulting current globally corresponds to the photosynthetic 
electron rerouting from the algae. This photocurrent increased until reaching a steady state value that eventually diminishes at long timeframes. Furthermore, the fast decrease of the photocurrent after turning light off shows that the electron harvesting results from the photosynthetic electron transfer chain (PETC).

In order to provide some further insights into the research of the most appropriate quinones, we took benefit from previous works by screening several structures with this setup (Table 1). Furthermore, two Chlamydomonas reinhardtii strains were investigated. The wild type (WT) strain corresponds to a fully functional photosynthetic electron transfer chain. The $\Delta$ petA mutant lacks the $\mathrm{b}_{6} f$ complex so the electron flow is interrupted downstream of the plastoquinone pool. ${ }^{[15]}$ As evidenced in Table 1, the best current is measured for WT algae with 2,6-DCBQ $\left(I_{\max }=(22.3 \pm 3.9) \mu \mathrm{A}\right.$, i.e. $\left.35 \mu \mathrm{A} \mathrm{cm}{ }^{-2}\right)$. This is consistent with the fact that 2,6-DCBQ is one of the most oxidizing agents (in terms of $\mathrm{E}^{\circ}$ values for $\mathrm{QH}_{2} / \mathrm{Q}$ at $\mathrm{pH} 7$ and $\left.\mathrm{Q}^{-} / \mathrm{Q}\right)$ and therefore a good PSII acceptor. Furthermore, the recorded photocurrents are still lower with $\Delta$ petA mutants. The differences are relatively small for the most efficient quinones (DCBQs and PPBQ) but very high for the two methylbenzoquinones. All in all, it suggests that the exogenous quinones readily act as PSII acceptors but can also interact downstream of the $\mathrm{b}_{6} f$ complex, for instance with PSI acceptors. This trend was already observed for 2,6DMBQ in previous fluorescence experiments. ${ }^{[10 \mathrm{a}]}$ In other words, some bad PSII acceptors can reroute the electron flow from another part downstream of the PETC. Furthermore, hindered quinones with electron donor groups (DQ; 2,5-( $\left.{ }^{\mathrm{t}} \mathrm{Bu}\right)_{2} \mathrm{BQ} ; 2$,6- $\left({ }^{\mathrm{t}} \mathrm{Bu}\right)_{2} \mathrm{BQ}$ ) lead to low photocurrents according to a lower ability to accept electrons. Figure 3 therefore show a quite good correlation between standard potentials with the maximum photocurrent. $\mathrm{E}^{\circ}\left(\mathrm{QH}_{2} / \mathrm{Q}\right)$ at $\mathrm{pH} 7$ displays the whole oxidizing power (Figure 3A) while $\mathrm{E}^{\circ}\left(\mathrm{Q}^{-} / \mathrm{Q}\right)$ is more related to the first electron transfer between $Q$ and the reduced species within the photosynthetic chain (Figure 3B). Whatever the considered standard potential is, the maximum photocurrent is globally correlated to the oxidizing properties of the considered quinone. Of note, BQ does not follow this trend. It shows that the redox potential may still not be a key parameter. Indeed, BQ is an unhindered quinone which can easily react as a Michael acceptor (see below).

Another interesting result is related to the stability of the photocurrent. Indeed, the photocurrents readily reach a steady state value before slowly decreasing (Figure 2B). This decrease depends on the quinone (Table 1) and cannot be predicted by the electrocatalysis process alone. This suggests concomitant poisoning effects due to quinones. ${ }^{\left[11 \mathrm{a},{ }^{12]}\right.}$ In our 
experiments, highly rerouting quinones (2,6-DCBQ or PPBQ) lead to moderate steady state photocurrent duration while low PSII accepting quinones (DMBQs, DQ) involve more stable photocurrents (Table 1).

Because a correlation is supposed between the "poisoning" effect of quinones (i.e. in terms of photocurrent decrease) and their oxidizing properties, the effects of quinones were also investigated in absence of electrocatalysis.

\subsection{Effects of quinones on the algae without electrocatalysis}

\subsection{1. $\quad$ Algae incubation with exogenous quinones - Effects on $\Phi_{P S I I}$}

An interesting way to investigate the unexpected effects of quinones is to estimate the quantum yield of PSII chemistry $\left(\Phi_{\mathrm{PSII}}\right)$ by fluorescence measurements. This corresponds to the fraction of absorbed light by PSII chlorophylls used in photochemistry (i.e being converted in photosynthetic electron flow from PSII). ${ }^{[19]}$ Briefly, induction fluorescence curves are the usual analytical tool to calculate this parameter. To obtain these curves, chlorophyll fluorescence emission is measured during illumination of the algae suspension. Indeed, light is captured by PSII that leads to a charge separation (P680-pheo- $\mathrm{Q}_{\mathrm{A}} \rightarrow \mathrm{P} 680^{+}-$ pheo- $\mathrm{Q}_{\mathrm{A}}{ }^{-}$) and especially the reduction of the primary acceptor $\mathrm{Q}_{\mathrm{A}}$ into $\mathrm{Q}_{\mathrm{A}}{ }^{-}$(Figure 1A). Under steady state actinic light, a fraction of $\mathrm{Q}_{\mathrm{A}}$ is reduced and a fraction of $\mathrm{Q}_{\mathrm{A}}$ is oxidized, which gives an intermediate value of fluorescence $\left(F_{S}\right.$; see Figure $\left.4 \mathbf{A}\right)$. A supersaturating pulse then induces the full reduction of $\mathrm{Q}_{\mathrm{A}}$ and the maximum level of fluorescence $\left(\mathrm{F}_{\mathrm{M}}\right)$. $\Phi_{\mathrm{PSII}}$ thus corresponds to the fluorescence yield $\left(\mathrm{F}_{\mathrm{M}}-\mathrm{F}_{\mathrm{S}}\right) / \mathrm{F}_{\mathrm{M}}$.

In these experiments, WT algae suspensions were incubated with four representative quinones (at $100 \mu \mathrm{mol} \mathrm{L}{ }^{-1}$ ), the fluorescence was followed during a $4 \mathrm{~s}$ illumination and the values of $\Phi_{\text {PSII }}$ were measured at the end of this light period (Figure 4A). As displayed in Figure 4B, the quantum efficiency of PSII is altered after incubation with quinones for three of them (2,6-DCBQ, PPBQ, 2,6-DMBQ). Conversely, $\Phi_{\mathrm{PSII}}$ remains constant for DQ although the initial value is already diminished due to the quinone. Furthermore, no effect was observed with the hydroquinone forms. The decrease for 2,6-DCBQ, 2,6-DMBQ and PPBQ is globally consistent with previous experiments where the quinones have been shown to act in different ways. First, quinones are known to perform non-photochemical quenching of chlorophyll fluorescence. ${ }^{[20]}$ They indeed interact with excited chlorophyll, decrease the 
lifetime of the exciton in PSII antenna and thus decrease the available light for charge separation. Furthermore, the production of additional quenchers during the incubation was already observed in the PPBQ case for previous works. ${ }^{[12]}$ Second, quinones can react as Michael acceptors and alter the microorganism. ${ }^{[21]}$ The case of DQ is more difficult to rationalize because the $\Phi_{\text {PSII }}$ value did not significantly vary but remained quite low compared to the case without quinones. This intrinsic moderate ability to harvest photosynthetic electrons from the beginning to the end of the incubation is consistent with an inhibiting behavior. The quinone may thus be maintained at the extraction site without being reduced due to its low redox potential. It would result in an "inverted" zone where the quinone interrupts the chain and decreases the fraction of $\mathrm{Q}_{\mathrm{A}} \cdot{ }^{\left[{ }^{9 b]}\right.}$ More generally, it is worth mentioning that the quite fast quenching behavior of quinones makes difficult the observation of the expected increase of $\Phi_{\text {PSII }}$ that can be measured only under peculiar conditions. ${ }^{[22]}$

As a first conclusion, the decrease in $\Phi_{\mathrm{PSII}}$, especially for PPBQ, may result from a combined role of quinones in terms of toxicity and quenching. Therefore, the $\Phi_{\text {PSII value did }}$ not properly correlate the photocurrent values. In order to go further, the ATP synthase activity and the cell growth after quinone incubation were monitored.

\subsubsection{ATP synthase activity}

During photosynthesis, electron transfer along the photosynthetic chain gives birth to a vectorial relocation of protons from the stroma to the lumenal space of the thylakoids. This displacement of protons across the membrane induces the creation of an electrochemical proton gradient $\left(\Delta \mu_{\mathrm{H}}{ }^{+}\right)$or proton motive force (pmf) that includes two components: a proton concentration gradient $(\Delta \mathrm{pH})$ and an electric field $(\Delta \psi)$. The $\Delta \mu_{\mathrm{H}}{ }^{+}$has a key role in photosynthesis by providing the energy required for the synthesis of ATP produced by ATP synthase. ${ }^{[23]}$ The $\Delta \mathrm{pH}$ plays the role of modulator of the rate of electron transfer and sets off de-excitation of surfeit light in the bosom of photosynthetic light harvesting complexes. ${ }^{\text {[24] }}$ The presence of this electric field induces a slight shift in the energy levels of some photosynthetic pigments present in the thylakoid membrane. This consequently changes their absorption spectra, due to the Stark effect, and induces an electrochromic Shift (ECS). ${ }^{[25]}$ The light-induced variation of the absorption spectrum provides information on the proton motive force across the membrane and, therefore, the functioning of ATP synthase. ${ }^{[26]}$ Effectively, in 
the majority of photosynthetic systems and especially in Chlamydomonas, the ECS signal is linear as a function of the intensity of the electric field.

The kinetic analysis of the ECS signal following a saturating laser flash makes it possible to bring out three different phases. This data treatment is possible by using repetitive flash spectroscopy to synchronize photosynthetic samples for kinetic resolution and signal to noise ratio improvements. ${ }^{[27]}$ Saturating laser flashes allow the excitation of all photosystems at a time, but are too short to allow two charge separations in the same photosystem. The first very faster rise "a phase" of the ECS signal (in pink in Figure 5A) corresponds to a rapid increase of the electric field created by the charge separation in PSI and PSII which time scale range is below the kinetic measurement resolution, it corresponds to less than $100 \mu$ s. This phase is followed by a slower rising phase (called "b phase" and lasting few tens of ms) (in blue in Figure 5A) correlated with the turnover of the complex $\mathrm{b}_{6} f$ which couples electron movement from plastoquinol to plastocyanin and the pumping of extra protons across the thylakoid. ${ }^{[27]}$ Finally, after the end of this "b phase", there is a decrease in the electric field ("c phase"). In native chloroplasts, this ECS decay (in green in Figure 5A) lies in the charge leakage mostly due to the consumption of the proton gradient by the ATP synthase that reduces the electric field. Therefore, the variation in relaxation time of the ECS signal provides information on the level of activity of the corresponding enzyme (e.g., "a phase" on number of active photosystems, "b phase" on activity of cytochrome $\mathrm{b}_{6} f$ and "c phase" on ATP synthase activity, respectively).

We measured the flash-induced ECS kinetics in the presence of various quinones in order to look at their effect on the ATP synthase activity. The addition of exogenous quinones clearly slowed down the relaxation of ECS ("c phase"; Figure 5B) with the highest effect measured with 2,6-DCBQ. Conversely, DQ does not induce any disturbance. The results obtained are generally in line with previous studies, namely that DQ has almost no disturbance effect unlike quinones such as 2,6-DCBQ and to a lesser extent 2,6-DMBQ. This slow-down of ATPase activity can be explained if $1 /$ it is inhibited directly by quinones or 2 / if quinones indirectly affect the $\operatorname{pmf}\left(\Delta \mu \mathrm{H}^{+}\right)$present before the flash since there is an ATPase activation threshold by the pmf. ${ }^{[28]}$ Here, the ECS increase and relaxation in response to a few ms pulse of saturating light allows one to discriminate between these two options. At the end of such a pulse, the electric field generated is $\sim 5$ fold higher than after a flash (Figure S1 vs Figure 5B) and all treatments show a comparably fast initial decay of the electric field, which demonstrates that the ATPase is not intrinsically inhibited by exogenous quinones. Instead, 
for the quinones which slowdown the ATPase activity after a flash, a typical pulse-induced ECS relaxation at low dark pmf is obtained, comprising a fast and a slow phase. ${ }^{[29]}$ This validates the second hypothesis, where the slower "c phase" reflects a weaker pmf in the dark (ie before the flash), which is in equilibrium with the ATP/ADP ratio in the chloroplast. This may represent a lower ATP concentration under these conditions because respiration is inhibited by quinones. Among the investigated quinones, the most harvesting quinone $(2,6-$ DCBQ, PPBQ) are the more active towards the relaxation phase while poor accepting quinones (2,6-DMBQ, DQ) lead to moderate effects.

Another (indirect) effect can be observed on those flash-induced ECS kinetics and relate to the extent of "b phase". Indeed, it is a common observation that in oxic conditions, wild type cells do not show a "b phase" because it is bypassed by the fast relaxation of ECS by the ATPase activity. However, in the presence of 2,6-DMBQ, 2,6-DCBQ or PPBQ, the "c phase" becomes several orders of magnitude slower than the "b phase" (few seconds vs 10-20 $\mathrm{ms})$. The "b phase" is thus expected to appear but is still not observed. This probably shows that the $\mathrm{b}_{6} f$ is decorrelated from the rest of the photosynthetic chain and confirms that these quinones completely bypass the photosynthetic chain.

\subsubsection{Cell growth}

An interesting way to observe the poisoning effect of quinones is to estimate their effect on the algae proliferation during their culture. To do so, wild-type algae were incubated with different quinone concentrations under experimental conditions used for chronoamperometry (micromolar range; one hour). Their growth rate and doubling time are then compared to a control experiment, i.e., without any quinone incubation. It consequently allows us to deduce the fraction of cells capable of growing after incubation with quinones. As a result, we define two threshold concentrations: $\mathrm{CC}_{20}$ and $\mathrm{CC}_{80}$ which correspond to quinone concentrations where 80 and $20 \%$ of cells still grow, respectively. Quinones leading to a fast current decrease thus correspond to CC values much less than $100 \mu$ mol.L ${ }^{-1}$ (Table 2). As an example, 2,6-DCBQ is a quinone that prevents the cell growth at relatively low concentration. A similar effect was recently observed in the case of cyanobacteria. ${ }^{[6 \mathrm{~b}]}$ The results are in agreement with a redox potential-activity relationship. The less oxidizing quinones (i.e., with low redox potential; DMBQ, DQ) did not lead to a significant poisoning whereas the most oxidizing quinones (DCBQ, PPBQ) show low CC values where they may 
act as poisons. Among the considered quinones, a correlation can be established between the ability to reroute photosynthetic electrons and a poisoning behavior. While this does not concern algae, this fact was already observed for quinones towards hepatocytes and was attributed to the ability of electrophilic quinones to form addition products with $\mathrm{GSH} .{ }^{[30]}$ Moreover, the hydroquinone forms have no effect on the cell growth under the same conditions. Furthermore, sterically hindered quinones (for methyl substituents for DQ or tertio-butyl substituants for $\left.\left({ }^{\mathrm{t}} \mathrm{Bu}\right)_{2} \mathrm{BQ}\right)$ are clearly non-toxic in the usual concentration used in chronoamperometry. The electron-donor groups obviously involve a very low redox potential that does not fit the requirements for harvesting photosynthetic electrons. However, it paves the way for using hindered quinones whose redox potential will be high enough to extract electrons from the photosynthetic chain.

\subsection{Investigation of other quinones}

From the above-mentioned results, we see that electron harvesting and poisoning behaviours are both related to oxidising (i.e., with a high redox potential) and/or poorly substituted quinones. As a result, we chose to work with quinones bearing both electronwithdrawing and donor groups as a compromise. This is the case of 2,5-dichloro-3,6dimorpholine-1,4-benzoquinone (DCMorBQ), 2,5-dichloro-3,6-di-tert-butylthio-1,4benzoquinone (DCThioBQ) and 2,3-dimethyl-4-phenyl-1,4-benzoquinone (DMPPBQ).

DCMorBQ corresponds to a quinone moiety bearing two electron-withdrawing chloride atoms and two electron-donating morpholine groups. As shown by cyclic voltammetry experiments, DCMorBQ is less oxidising than 2,6-DCBQ (Figure S2). A first interesting result is related to the absence of effects of DCMorBQ towards algae proliferation

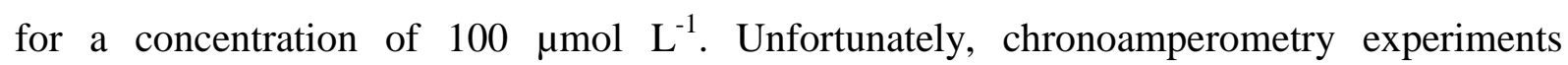
evidenced that the photocurrent recorded for $2 \times 10^{7}$ cells $\mathrm{mL}^{-1}$ and $100 \mu \mathrm{mol} \mathrm{L}{ }^{-1}$ of DCMorBQ is less than $1 \mu \mathrm{A}$ (Figure 6). It means that adding two morpholine groups to 2,6-DCBQ makes the resulting quinone not able to harvest electrons from the PETC. Induction fluorescence experiments (Figure S3) suggest that DCMorBQ would inhibit electron transfer with the PETC because the fluorescence level under actinic light did not significantly change after applying the supersaturating pulse (ie $\Phi_{\mathrm{PSII}} \sim 0$ ). This result would be consistent with an irreversible interaction between DCMorBQ and the $\mathrm{Q}_{\text {в }}$ pocket by means of nitrogen donor atoms that lead to a complete reduction of $\mathrm{Q}_{\mathrm{A}}$ in the light. 
In a similar idea, DCThioBQ corresponds to 2,5-DCBQ substituted with two tertbutylthiolate groups. Unfortunately, cyclic voltammetry evidences that the redox potential of DCThioBQ is not significantly altered by comparison with 2,5-DCBQ (Figure S4). Furthermore, due to the thioether group, DCThioBQ is easily adsorbed on gold electrode. Finally, even at low concentrations $\left(10 \mu \mathrm{mol} \mathrm{L} \mathrm{L}^{-1}\right)$, DCThioBQ prevents algae proliferation and even induces degradation of algae (the green color rapidly turns red). Therefore, no chronoamperometry experiment was achieved with this inappropriate quinone.

As mentioned above, functionalizing the DCBQ moiety did not lead to convincing results. As a consequence, the third quinone we considered was formally a structural mix between a rerouting (PPBQ) and a non-poisoning quinone (DMBQ), i.e. 2,3-dimethyl-4phenyl-1,4-benzoquinone (DMPPBQ). Interestingly, this quinone resembles plastoquinone where a phenyl group replaces the isoprenyl side chain. From an electrochemical point of view, the redox behaviour of DMPPBQ is similar to that of 2,3-DMBQ (2,3-dimethyl-benzo1,4-quinone) as evidenced in cyclic voltammetry (Figure S5). It allowed us to find that its oxidizing properties in terms of $\mathrm{E}^{\circ}\left(\mathrm{QH}_{2} / \mathrm{Q}\right)$ is similar to DMBQs. Like DQ or DCMorBQ, no effect of DMPPQ towards algae proliferation was observed for a concentration of $100 \mu \mathrm{mol}$ $\mathrm{L}^{-1}$. These preliminary results suggest that DMPPQ may combine appropriate properties for rerouting photosynthetic electrons without leading to significant poisoning effects at a concentration of $100 \mu \mathrm{mol} \mathrm{L}{ }^{-1}$. As a result, this trend is confirmed by chronoamperometry measurements that evidence a stable photocurrent $(5.8 \pm 0.8 \mu \mathrm{A})$ over the time period considered in our studies (Figure 6).

Among the investigated quinones, DMPPBQ gives the best result in terms of stable photocurrent: it corresponds to a significant photocurrent with the best stability. In other words, all the quinones leading to a higher photocurrent (2,6-DCBQ, PPBQ, DMBQs) concomitantly imply a decrease in stability.

\subsection{Discussion}

In this work, we screened different quinones from highly (DCBQ, PPBQ) to moderately oxidizing ones (DMBQs, DQ). It obviously raises the question of the ideal exogenous quinone to harvest photosynthetic electrons from algae suspensions. While it may not be a definitive trend, we observed a relationship between the oxidizing properties of the 
considered quinone and the stability of the photocurrent (Table 2). Figure 7A thus depicted the maximum photocurrents obtained with quinones at $100 \mu \mathrm{mol} . \mathrm{L}^{-1}$ as a function of the stability of such a photocurrent. This confirms that the most rerouting quinones are also the most poisoning ones because the harvesting effect of a high concentration $\left(100 \mu \mathrm{mol} . \mathrm{L}^{-1}\right)$ is fastly countered by the side effects of the considered quinone (see also Figure S6). As a result, a high redox potential will globally lead to high but unstable photocurrents due to quinone toxicity. Conversely, a low redox potential should lead to a stable but quite low photocurrent.

A second interesting analysis is to consider concentration ranges where the maximum photocurrent remains stable. Figure 7B shows the stable maximum photocurrents (measured at $\mathrm{CC} 20$ ) as a function of a nearly non toxic concentration (i.e. CC20). It is worth mentioning that similar photocurrents for 2,6-DCBQ, PPBQ, 2,6-DMBQ and DMPPBQ are observed provided that the highest non toxic quinone concentrations were used. This evidenced a "shift effect' related to the tuning of quinone concentration. For instance, 2,6-DMBQ and 2,6DCBQ correspond to very different quinones in terms of structure and redox potential but give similar performances if used at 10 and $40 \mu \mathrm{mol} \mathrm{L}^{-1}$, respectively. Furthermore, the comparison of intrinsic oxidising ability of quinones (resulting from $\mathrm{E}^{\circ}$ values and calculated by the ratio of the maximum stable photocurrent to the highest non toxic concentration) is well respected within non toxic quinone concentration ranges (Figure 7C). This confirms the role of quinone concentration and its side effect beyond toxic threshold concentrations.

All in all, the choice of the appropriate quinone for rerouting photosynthetic electrons from Chlamydomonas reinhardtii algae relies on some different parameters that should require a whole compromise. $1 /$ The redox potential reflects the oxidizing properties of the quinone that may lead to high but unstable photocurrents. This can be tuned by the subtituents of the quinone and their electronic effects. $2 /$ The substituents of the quinone also play a role if considering that they can alter the organism by means of Michael additions. A non-hindered quinone like BQ seems to easily react with nucleophiles. Most importantly, steric hindrance and electronic effects can be interconnected since substituted quinones with electrodonating groups both prevent electron harvesting and side effects. 3/ Performances can be tuned by adjusting the quinone concentration. Below a toxic threshold concentration, no poisoning occurs so similar performances for two quinones can be reached by adjusting the quinone concentration close to its highest non toxic value. 
Therefore, both quinone structure and concentration might finely tune their harvesting electron performances. Quinones both substituted with electron-donating and withdrawing groups thus appear as an interesting strategy. From this, DMPPBQ corresponds to significant stable performances without no concentration limits in the range of considered concentrations herein. As a result, DMPPBQ currently represents the best compromise with the best nontoxic concentration/photocurrent parameters couple.

\section{Conclusion}

In this article, we used a previously reported gold electrochemical device for investigating photosynthetic electron harvesting from algae suspensions by exogenous quinones. From this screening, we observed that the most rerouting quinones both lead to high but unstable maximum photocurrents. Beyond some now « usual » quinones (DCBQ, DMBQ, PPBQ), we have started investigating substituted and hindered quinones. Among them, DMPPBQ gave an interesting and stable photocurrent. However, taking into account the intrinsic performances of quinones and their toxicity makes the comparison more difficult to select the best candidate. Considering concentration ranges where the quinone is not toxic, DMPPBQ is consequently the best candidate and paves the way for future optimizations of the strategies involving quinones as redox mediators.

\section{Acknowledgements}

This work has been supported in part by CNRS (UMR 8640, UMR7141), Ecole Normale Supérieure, French Ministry of Research, Faculté des Sciences et Ingénierie - Sorbonne Universite and the "Initiative d'Excellence" program from the French State (Grant "DYNAMO", ANR-11-LABX-0011-01). M.G.-C. thanks Institut Universitaire de France Fellowship Program. 
Figure 1

A)

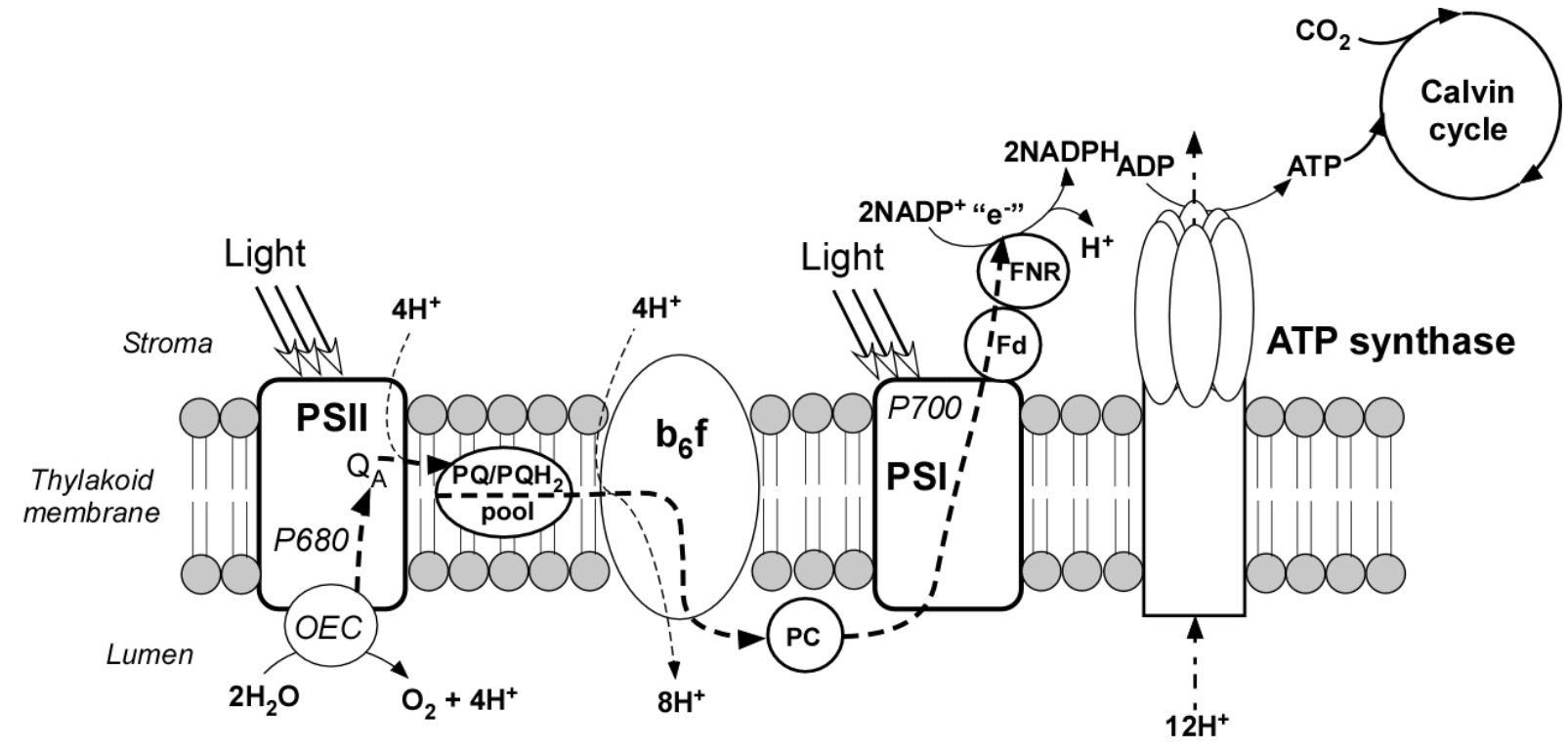

B)
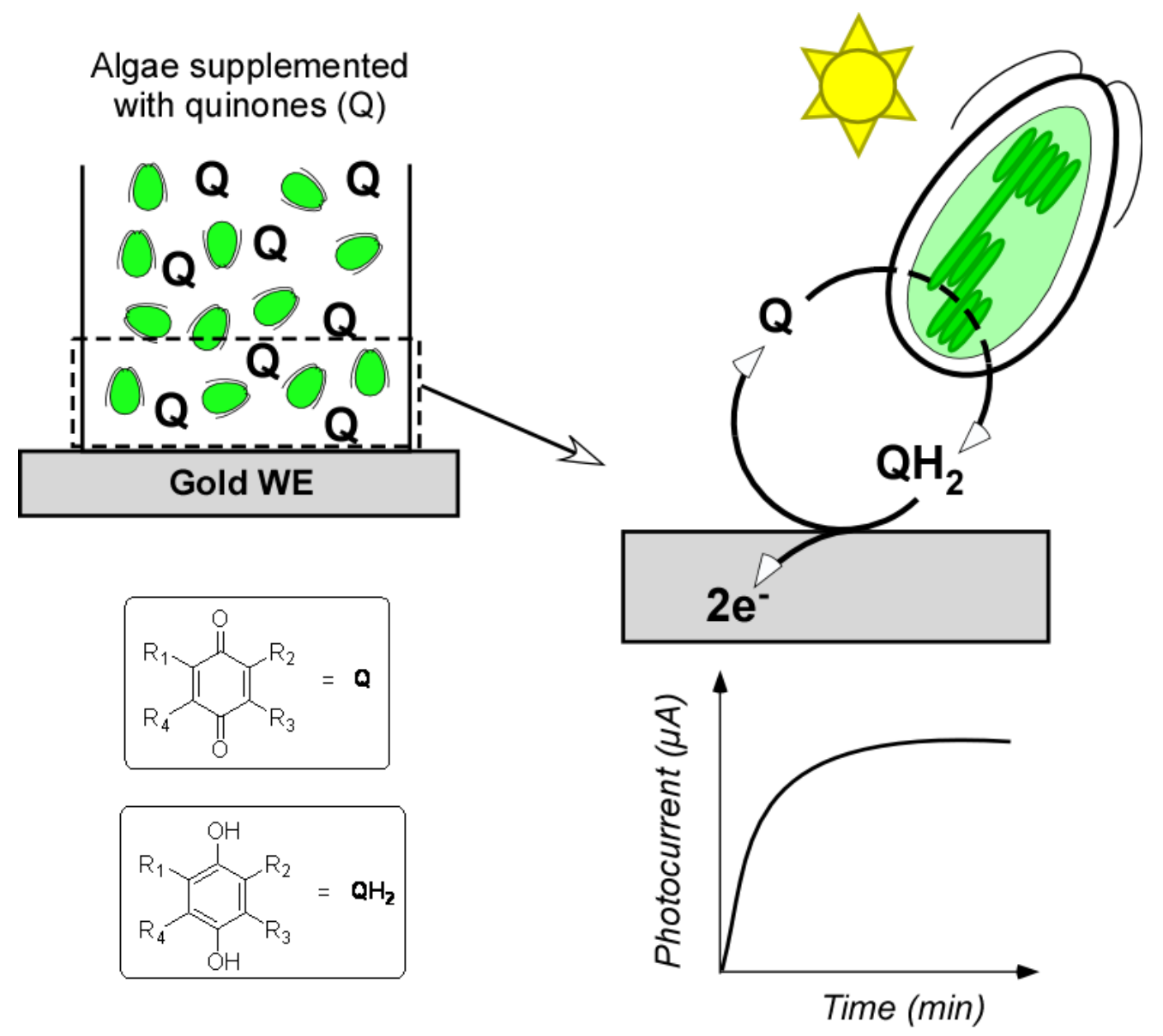


\section{Figure 2}

A)<smiles>O=C1C=CC(=O)C=C1</smiles>

Benzoquinone (BQ)<smiles>CC1=CC(=O)C=C(C)C1=O</smiles>

2,6-Dimethylbenzoquinone

$$
\text { (2,6-DMBQ) }
$$<smiles>O=C1C=CC(=O)c2ccccc21</smiles>

Naphthoquinone (NBQ)<smiles>O=C1C(Cl)=C(Cl)C(=O)C(N2CCOCC2)=C1Cl</smiles><smiles>O=C1C=C(Cl)C(=O)C(Cl)=C1</smiles>

2,6-Dichlorobenzoquinone (2,6-DCBQ)<smiles>CC1=CC(=O)C(C)=CC1=O</smiles>

2,5-Dimethylbenzoquinone (2,5-DMBQ)<smiles>CC(C)(C)C1=CC(=O)C(C(C)(C)C)=CC1=O</smiles>

2,5-di-tert-butylbenzoquinone $\left(2,5-\left({ }^{t} \mathrm{Bu}\right)_{2} \mathrm{BQ}\right)$<smiles>CC(C)(C)SC1=C(Cl)C(=O)C(SC(C)(C)C)=C(Cl)C1=O</smiles><smiles>O=C1C=CC(=O)C(c2ccccc2)=C1</smiles>

phenyl-p-benzoquinone (PPBQ)

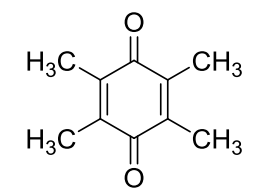

Tetramethylbenzoquinone (duroquinone; DQ)<smiles>CC(C)(C)C1=CC(=O)C=C(C(C)(C)C)C1=O</smiles>

2,6-di-tert-butylbenzoquinone $\left(2,6-\left({ }^{t} \mathrm{Bu}\right)_{2} \mathrm{BQ}\right)$<smiles>CC1=C(C)C(=O)C(c2ccccc2)=CC1=O</smiles>

2,5-Dichloro-3,6-dimorpholinobenzoquinone 2,5-Dichloro-3,6-di-tert-butylthiobenzoquinone 2,3-Dimethyl-5-phenylbenzoquinone (DCThioBQ) (DMPPBQ)

(DCMorBQ)

B)

\section{Light OFF}

\section{Light ON}

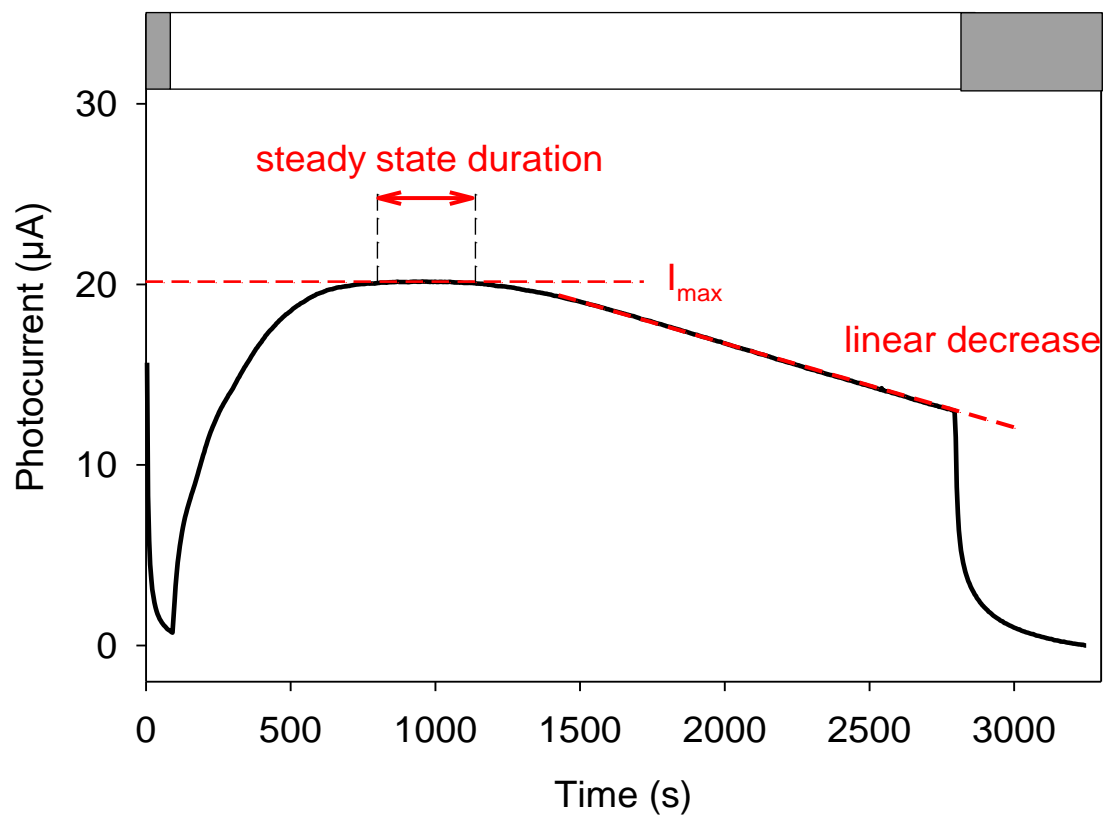


Figure 3

A)

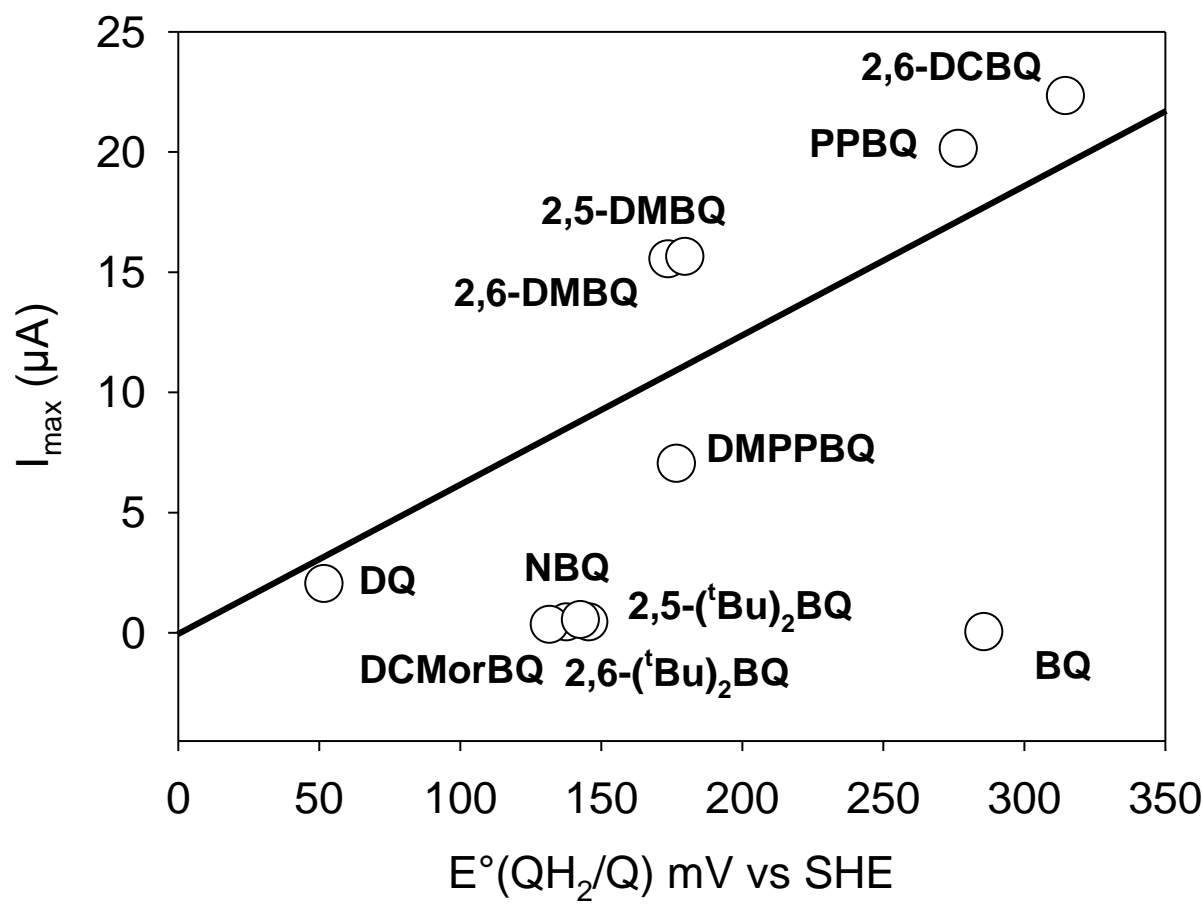

B)

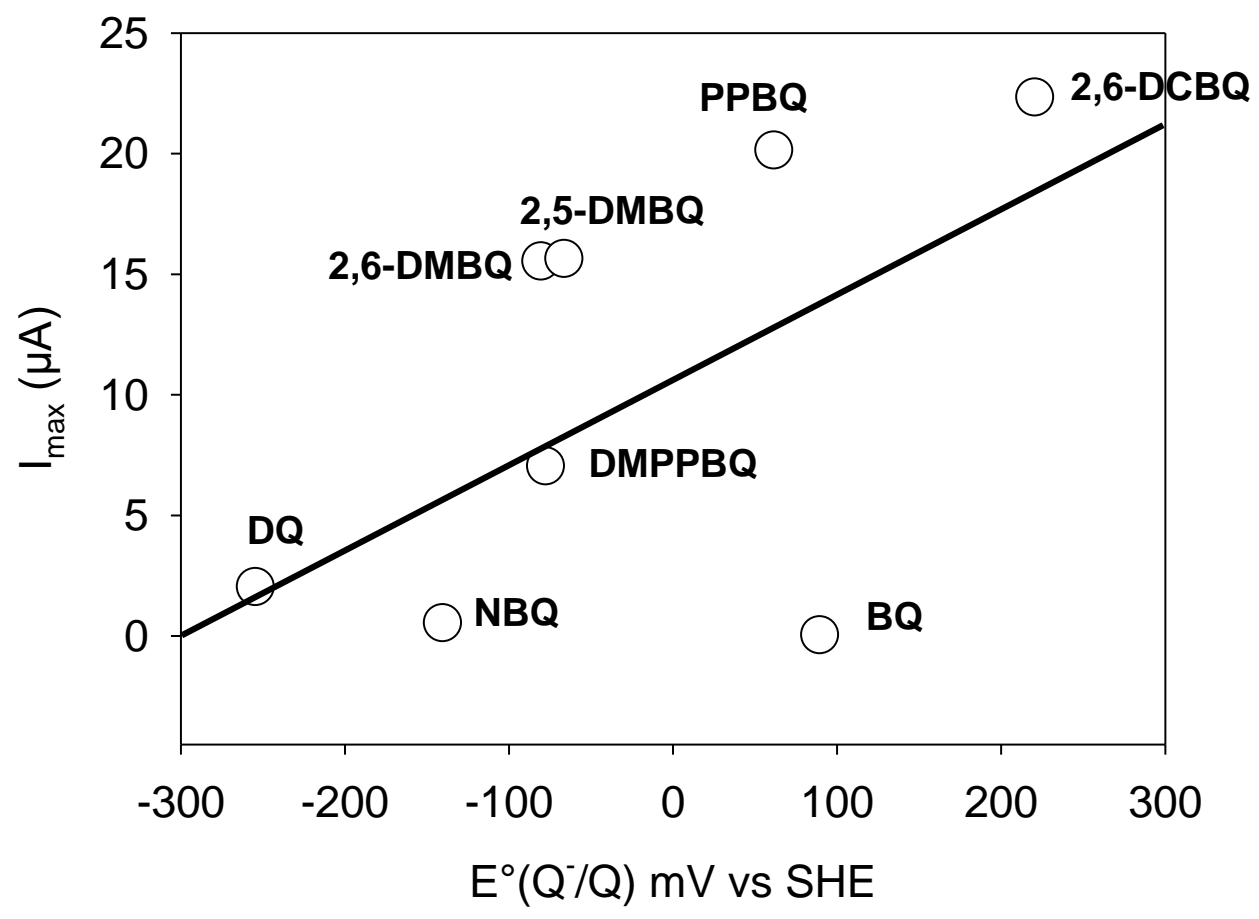


Figure 4

A)

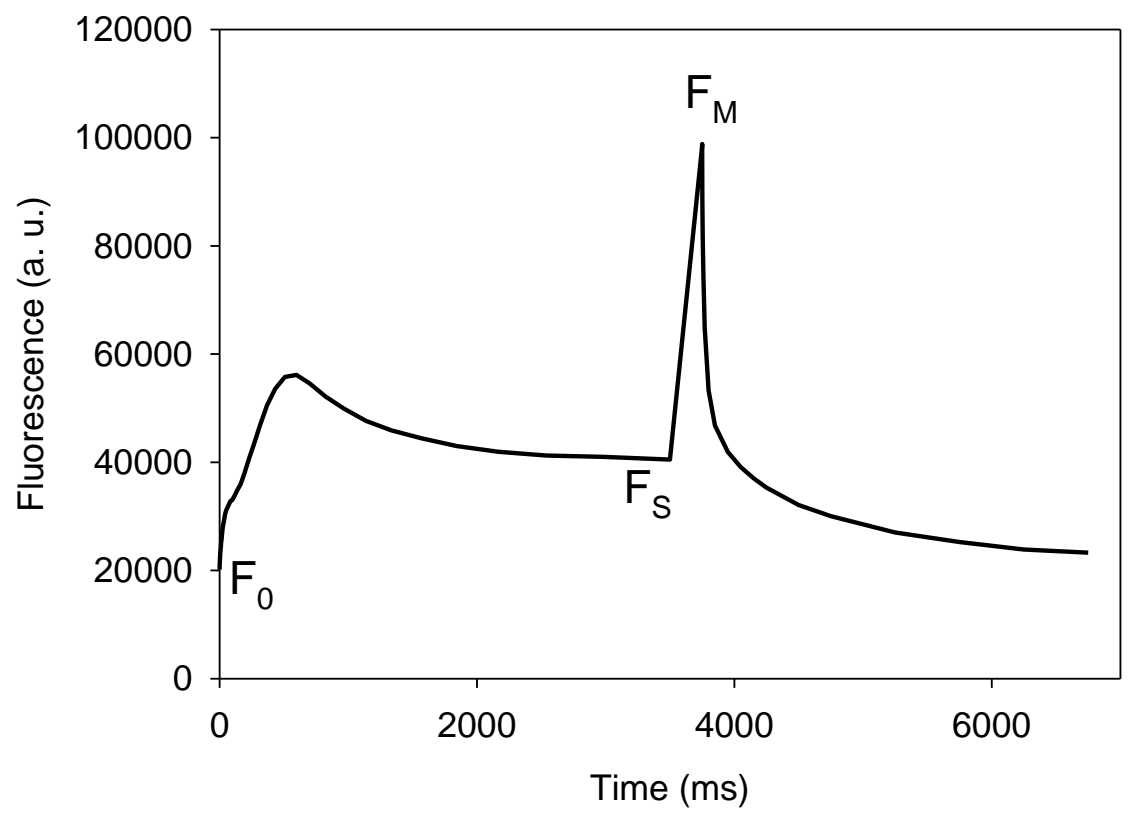

B)

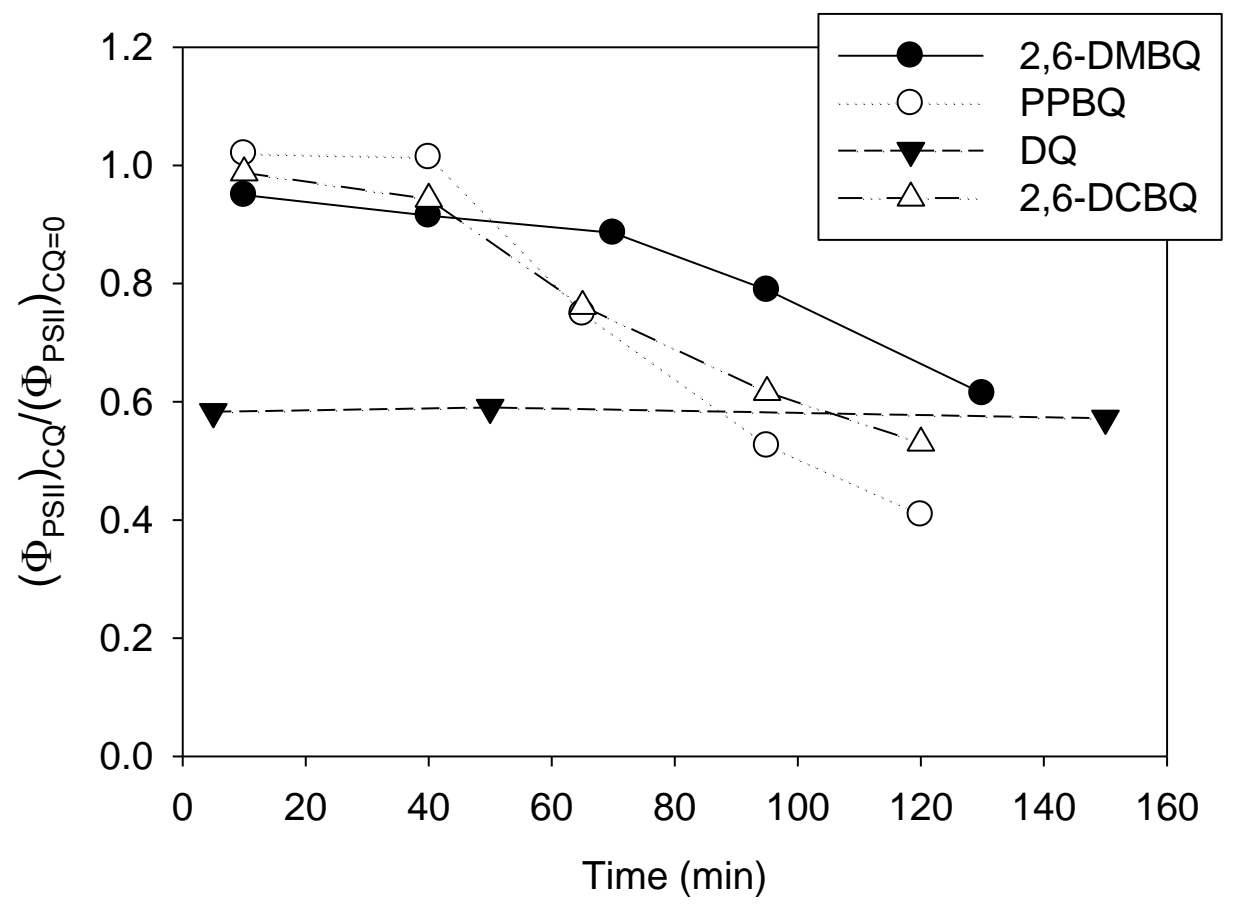


Figure 5

A)
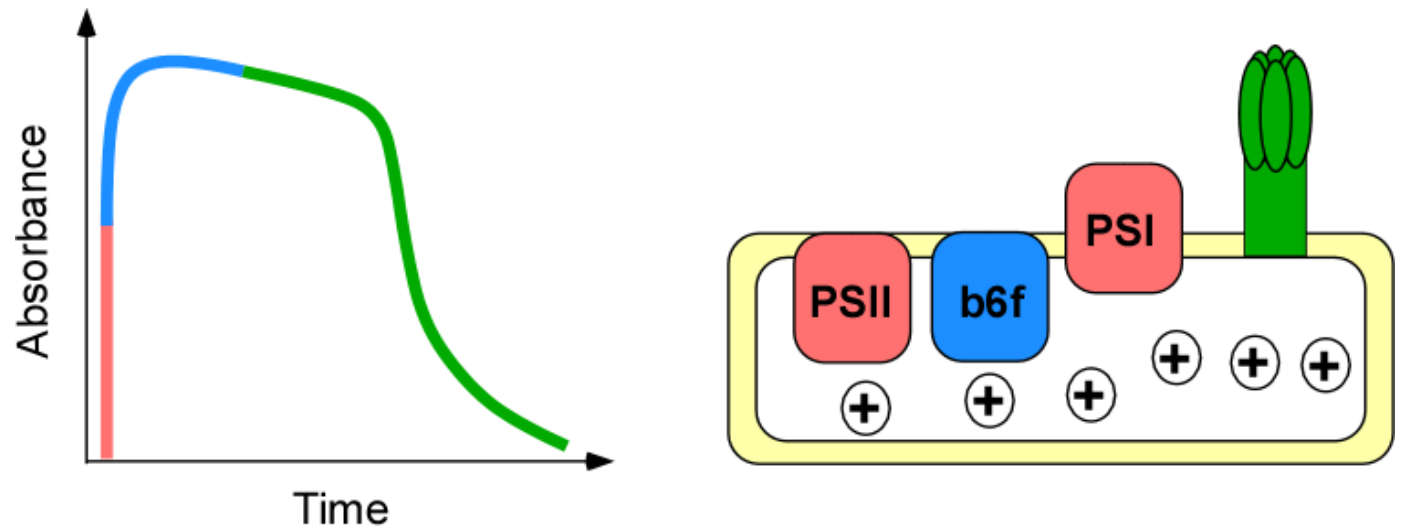

B)

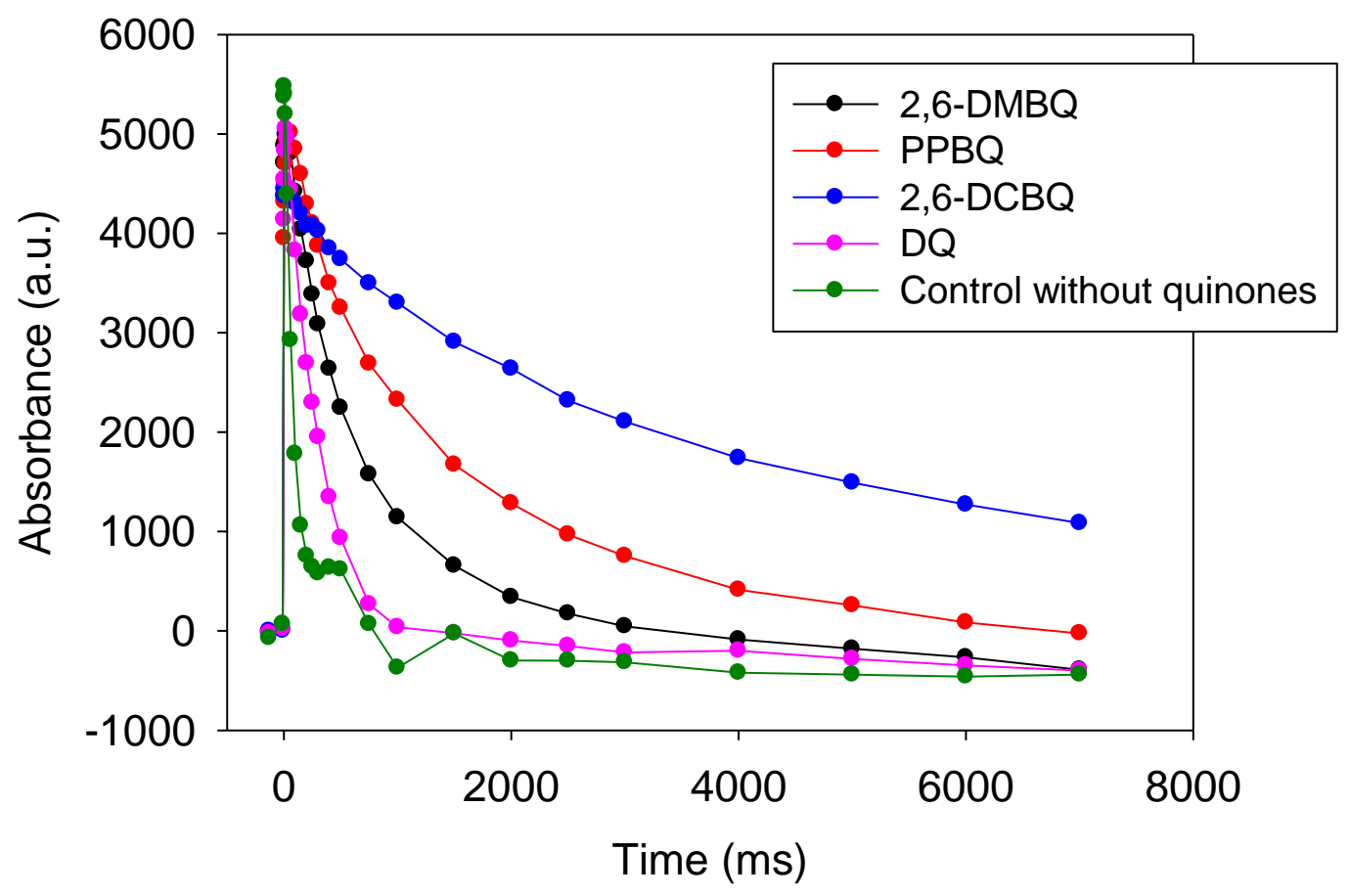


Figure 6

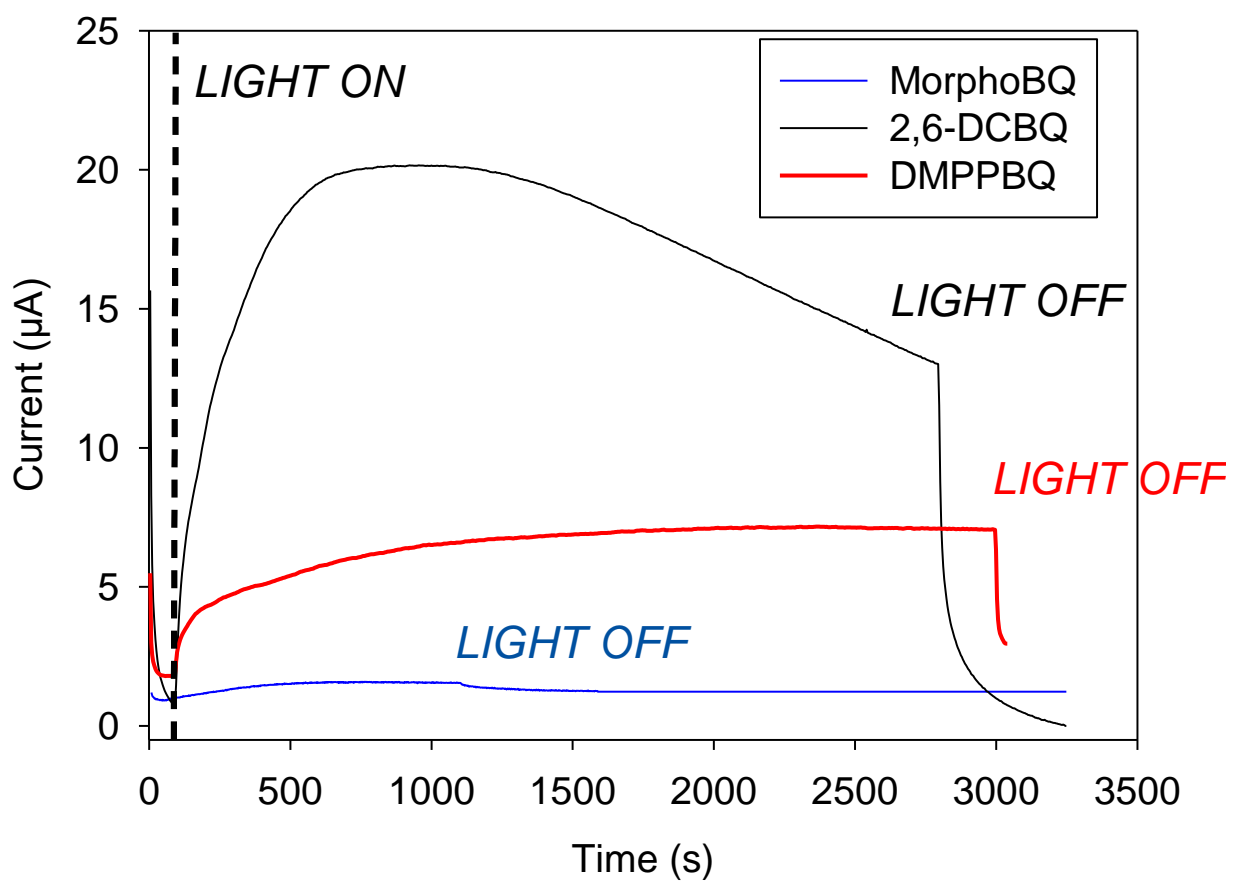


Figure 7

A)

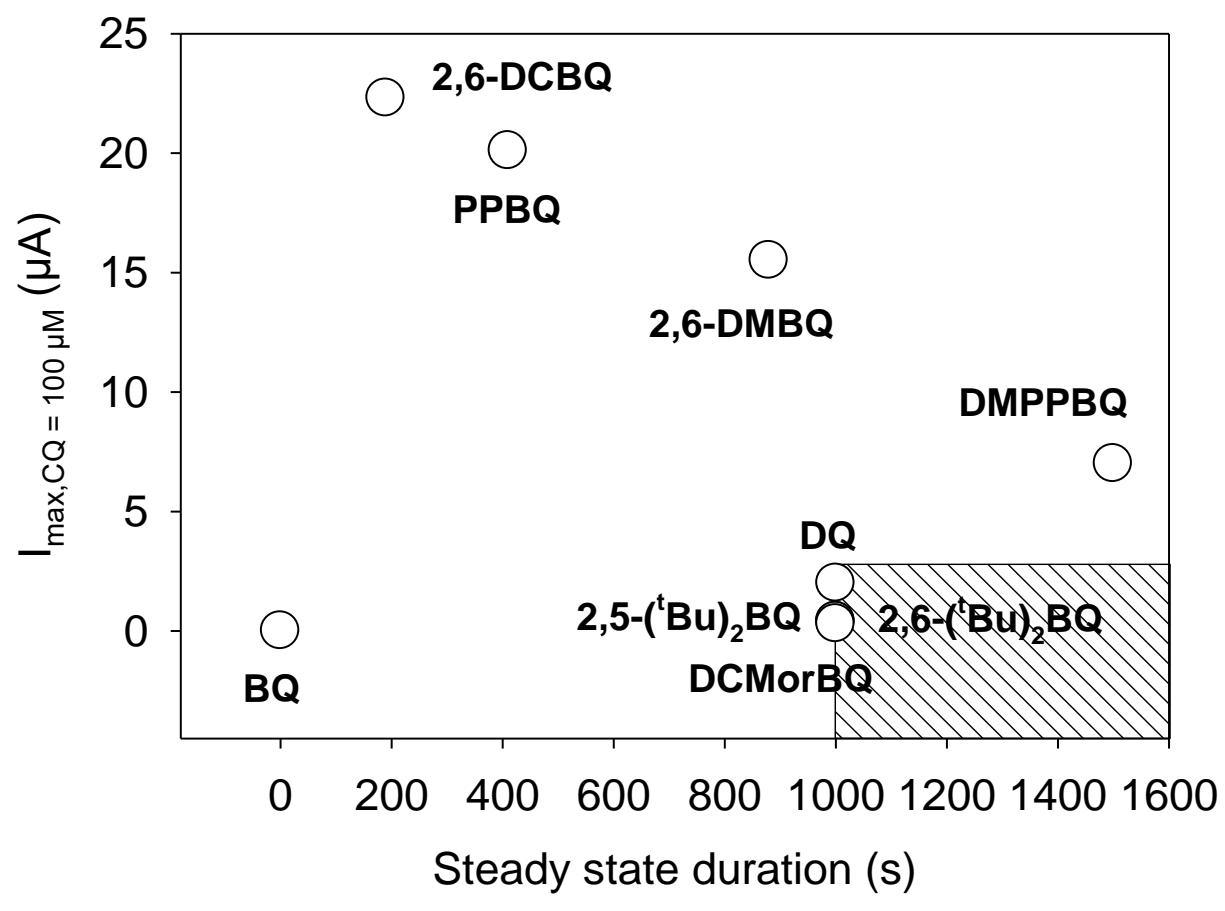

B)

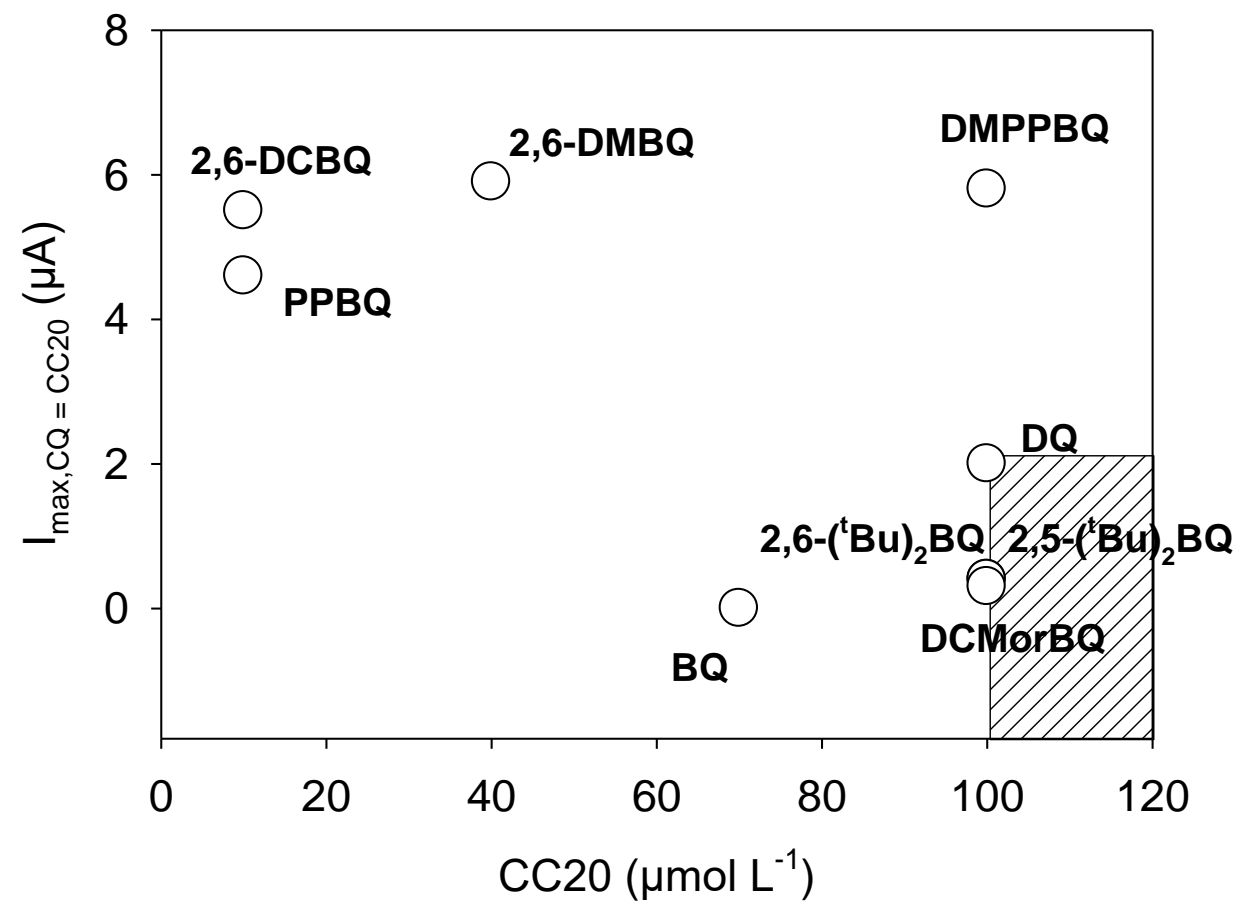


C)

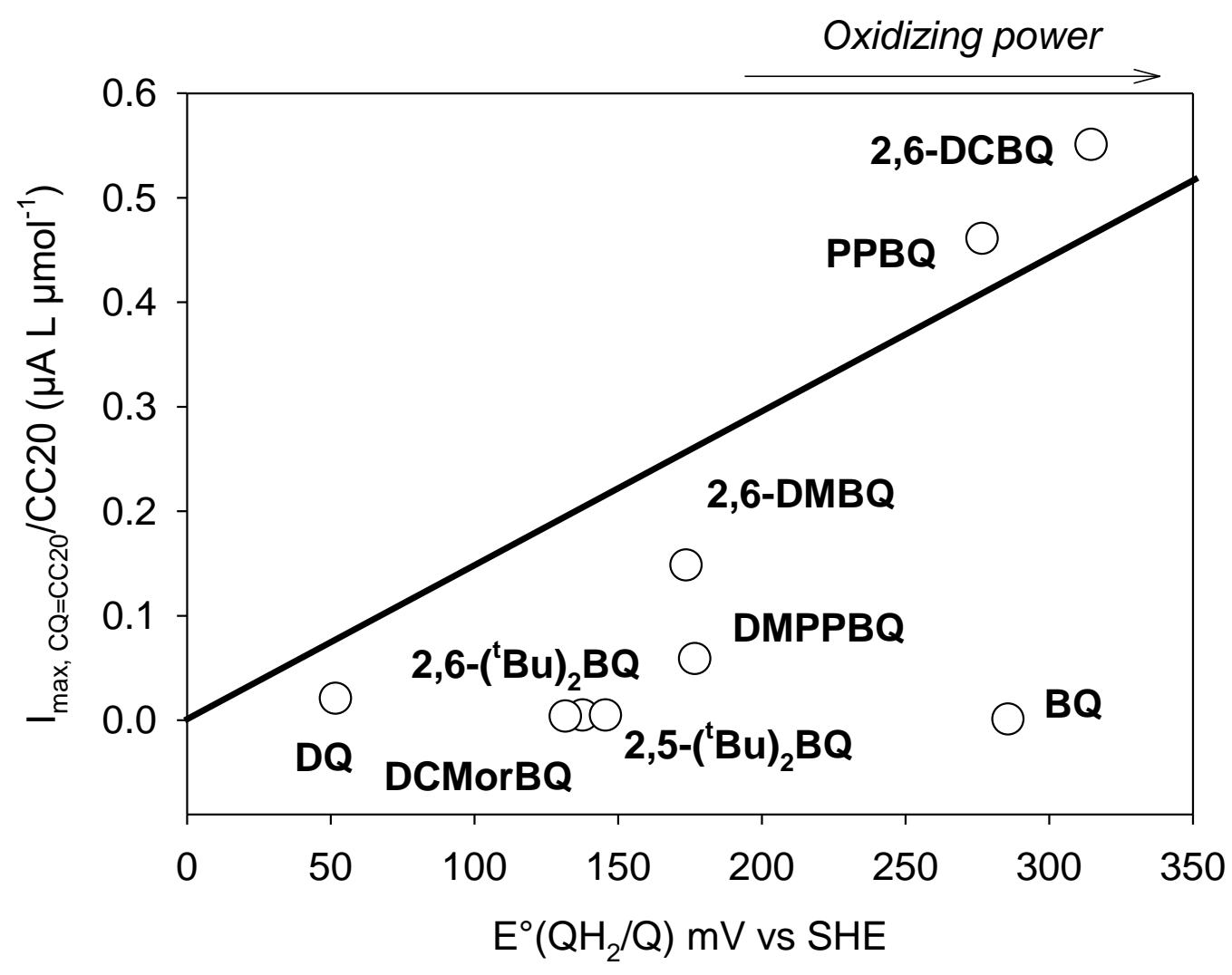




\section{Tables}

Table 1. Average values of photocurrents for different algae-quinone mixtures $\left(C_{Q}=100\right.$ $\mu \mathrm{mol} \mathrm{L}{ }^{-1}$ ). ${ }^{\text {a }}$ because $\mathrm{I}_{\max }$ is very low, the photocurrent appears quite stable overtime while slowly decreasing. The decrease is thus too low to be reliably extracted. ${ }^{b}$ For the same reasons, the steady state duration can be only estimated. ${ }^{c}$ Estimated by cyclic voltammetry. ${ }^{d}$ Estimated by analogy with 2,3-DMBQ. n.d: not determined. n.r: not reported.

\begin{tabular}{|c|c|c|c|c|c|c|c|}
\hline \multirow{2}{*}{$\begin{array}{c}\text { Quinone } \\
\text { (Q) }\end{array}$} & \multicolumn{2}{|c|}{ Photocurrent $(\mu \mathrm{A})$} & \multirow{2}{*}{$\begin{array}{c}\mathrm{I}_{\max }(\mathrm{WT}) / \\
\mathrm{I}_{\max }(\Delta p e t A \\
\text { mutant })\end{array}$} & \multirow{2}{*}{$\begin{array}{l}\text { Decrease in } \\
\text { photocurrent } \\
\text { for WT }\left(10^{3}\right. \\
\left.\mu \mathrm{A} \mathrm{s}^{-1}\right)\end{array}$} & \multirow{2}{*}{$\begin{array}{c}\text { Steady } \\
\text { state } \\
\text { duration } \\
\text { (s) }\end{array}$} & \multirow{2}{*}{$\begin{array}{c}\mathrm{E}^{\circ}\left(\mathrm{QH}_{2} / \mathrm{Q}\right) \\
\text { at } \mathrm{pH} 7(\mathrm{mV} \\
\text { vs SHE })\end{array}$} & \multirow{2}{*}{$\begin{array}{c}\mathrm{E}^{\circ}\left(\mathrm{Q}^{-} / \mathrm{Q}\right) \\
(\mathrm{mV} \text { vs } \\
\mathrm{SHE})\end{array}$} \\
\hline & WT & $\begin{array}{l}\Delta p e t A \\
\text { mutant }\end{array}$ & & & & & \\
\hline 2,6-DCBQ & $\begin{array}{c}22.3 \pm \\
3.9\end{array}$ & $\begin{array}{c}17.2 \pm \\
3.0\end{array}$ & $1.3 \pm 0.3$ & $5.0 \pm 0.8$ & $190 \pm 50$ & $315^{[31]}$ & $221^{[32]}$ \\
\hline PPBQ & $\begin{array}{c}20.1 \pm \\
3.5\end{array}$ & $\begin{array}{c}12.6 \pm \\
2.5\end{array}$ & $1.6 \pm 0.4$ & $2.1 \pm 0.4$ & $410 \pm 40$ & $277^{[33]}$ & $62^{[33]}$ \\
\hline 2,5-DMBQ & $\begin{array}{c}15.6 \pm \\
2.7\end{array}$ & $2.5 \pm 0.5$ & $6.2 \pm 1.6$ & $0.38 \pm 0.15$ & $810 \pm 90$ & $180^{[31,34]}$ & $-66^{[34]}$ \\
\hline 2,6-DMBQ & $\begin{array}{c}15.5 \pm \\
2.8\end{array}$ & $2.1 \pm 0.4$ & $7.4 \pm 1.9$ & $0.53 \pm 0.21$ & $880 \pm 90$ & $174^{[33]}$ & $-80^{[32,34]}$ \\
\hline DQ & $\begin{array}{c}2.0 \pm \\
0.5\end{array}$ & $<0.4$ & n.d. & $<0.2^{\mathrm{a}}$ & $>1000^{b}$ & $52^{[33]}$ & $-254^{[33]}$ \\
\hline $\begin{array}{c}2,6- \\
\left({ }^{\mathrm{t}} \mathrm{Bu}\right)_{2} \mathrm{BQ}\end{array}$ & $\begin{array}{c}0.4 \pm \\
0.1\end{array}$ & n.d. & n.d. & $<0.2^{\mathrm{a}}$ & $>1000^{b}$ & $138^{\mathrm{c}}$ & n.r. \\
\hline $\begin{array}{c}2,5- \\
\left({ }^{\mathrm{t}} \mathrm{Bu}\right)_{2} \mathrm{BQ}\end{array}$ & $\begin{array}{c}0.4 \pm \\
0.1\end{array}$ & n.d. & n.d. & $<0.2^{\mathrm{a}}$ & $>1000^{b}$ & $146^{[35]}$ & n.r. \\
\hline NBQ & $\begin{array}{c}0.5 \pm \\
0.1\end{array}$ & $0.4 \pm 0.1$ & $1.25 \pm 0.4$ & $<0.2^{\mathrm{a}}$ & $>1000^{b}$ & $143^{[31]}$ & $-140^{[36]}$ \\
\hline BQ & $\sim 0$ & $\sim 0$ & n.d. & n.d. & n.d. & $286^{[33]}$ & $90^{[33]}$ \\
\hline DCMorBQ & $\begin{array}{c}0.5 \pm \\
0.1\end{array}$ & n.d. & n.d. & $<0.2^{\mathrm{a}}$ & $>1000^{b}$ & $132^{\mathrm{c}}$ & n.r. \\
\hline DMPPBQ & $\begin{array}{c}5.8 \pm \\
0.8\end{array}$ & $1.1 \pm 0.4$ & $5.5 \pm 2.0$ & No decrease & 1500 & $177^{\mathrm{c}}$ & $-77^{d}$ \\
\hline
\end{tabular}


Table 2. Threshold concentrations for estimating the poisoning effect of some quinones. $\mathrm{CC}_{20}$ and $\mathrm{CC}_{80}$ correspond to quinone concentrations where 80 and $20 \%$ of cells still grow, respectively.

\begin{tabular}{|c|c|c|}
\hline Quinone & $\operatorname{CC80}\left(\mu \mathrm{mol} \mathrm{L} \mathrm{L}^{-1}\right)$ & $\operatorname{CC20}\left(\mu \mathrm{mol} \mathrm{L}^{-1}\right)$ \\
\hline 2,6-DCBQ & 20 & 10 \\
\hline PPBQ & 20 & 10 \\
\hline 2,6-DMBQ & 50 & 40 \\
\hline DQ & $>100$ & $>100$ \\
\hline $\mathrm{BQ}$ & 80 & 70 \\
\hline $2,6-\left({ }^{t} \mathrm{Bu}\right)_{2} \mathrm{BQ}$ & $>100$ & $>100$ \\
\hline $2,5-\left({ }^{t} \mathrm{Bu}\right)_{2} \mathrm{BQ}$ & $>100$ & $>100$ \\
\hline DCMorBQ & $>100$ & $>100$ \\
\hline DCThioBQ & $<10$ & $<10$ \\
\hline DMPPBQ & $>100$ & $>100$ \\
\hline
\end{tabular}




\section{Figure captions}

Figure 1. A) General scheme of the photosynthetic chain. Light is captured by light-harvesting complexes at the level of Photosystem II (PSII). Its subsequent excitation promotes energy transfer to P680 (that is the primary chlorophyll donor of PSII). The ensuing charge separation results in water oxidation by means of the Oxygen Evolving Complex (OEC) and reduction of the primary acceptor $\mathrm{Q}_{\mathrm{A}}$. Furthermore, electron transfer steps occur along the photosynthetic chain (oxydoreduction steps from plastoquinone (PQ) - plastoquinol $\left(\mathrm{PQH}_{2}\right)$ pool to plastocyanin (PC)) until the Photosystem I (PSI). A second excitation is then required and additional electron transfer pathways (Ferredoxin $(\mathrm{Fd}) \rightarrow$ Ferredoxin-NADP $^{+}$reductase $(\mathrm{FNR})$ ) eventually lead to the $\mathrm{NADP}^{+}$reduction. The resulting $\mathrm{H}^{+}$gradient triggers ATP production by means of ATP synthase. $\mathrm{CO}_{2}$ is finally reduced through the Calvin cycle which uses the products of the photochemical phase of photosynthesis, NADPH and ATP. B) Principle of the photocurrent production from the algae suspension. Chlamydomonas reinhardtii algae are suspended in physiological medium supplemented with quinones $(\mathrm{Q})$. It leads to the reduction of $\mathrm{Q}$ into hydroquinones $\left(\mathrm{QH}_{2}\right)$ by the photoexcited algae. The working gold electrode (reference and auxiliary electrodes are not shown for more clarity) is positioned at the bottom and poised at a potential value favoring the oxidation of $\mathrm{QH}_{2}$ into $\mathrm{Q}$ and the subsequent production of photocurrent.

Figure 2. A) Chemical structure of the quinones investigated in this work. B) Representative chronoamperometric trace $\left(\mathrm{P}=60 \mathrm{~mW} \mathrm{~cm}^{-2} ; \mathrm{E}_{\mathrm{W}}=0.38 \mathrm{~V}\right.$ vs $\left.\mathrm{Ag} / \mathrm{AgCl}\right)$ from a suspension of Chlamydomonas reinhardtii WT algae $\left(2 \times 10^{7}\right.$ cells $\left.\mathrm{mL}^{-1}\right)$ with $2,6-\mathrm{DCBQ}\left(100 \mu \mathrm{mol} \mathrm{L}{ }^{-1}\right)$. Light irradiance is displayed as a white rectangle. Before illumination, a background current is observed after electrode polarization, due to capacitive and faradic effects. ${ }^{[13]}$ Once the baseline remaining stable (after $\sim 90 \mathrm{~s}$ ), the illumination of the algae-quinone solution is triggered. The main parameters (maximum photocurrent, steady state period, photocurrent decrease) are displayed.

Figure 3. Maximum photocurrents measured for different quinones $\left(100 \mu \mathrm{mol} \mathrm{L} \mathrm{L}^{-1}\right)$ used with a WT algae suspension $\left(2 \times 10^{7}\right.$ cells $\left.\mathrm{mL}^{-1}\right)$ within the well gold/ITO device. A) as a function of $\mathrm{E}^{\circ}\left(\mathrm{QH}_{2} / \mathrm{Q}\right)$ at $\mathrm{pH}$ 7. B) as a function of $\mathrm{E}^{\circ}\left(\mathrm{Q}^{-} / \mathrm{Q}\right)$. DMPPBQ is assumed to have an $\mathrm{E}^{\circ}\left(\mathrm{Q}^{-}\right.$ /Q) close to that of DMBQs. 
Figure 4. A) Representative fluorescence induction curve (WT cells; $2.10^{7}$ cells $\mathrm{mL}^{-1} ; \mathrm{I}^{\circ}=$ $\left.135 \mu \mathrm{E} \mathrm{m}^{-2} \mathrm{~s}^{-1}\right)$. The initial fluorescence $\left(\mathrm{F}_{0}\right)$ corresponds to the dark-adapted state. After illumination, the fluorescence varies until a steady state level $\left(F_{S}\right)$ where the $\mathrm{Q}_{A} / \mathrm{Q}_{\mathrm{A}}{ }^{-}$ratio is constant. The surpersaturating and short light pulse fully reduces $\mathrm{Q}_{\mathrm{A}}$ into $\mathrm{Q}_{\mathrm{A}}{ }^{-}$. It helps to reach the maximum fluorescence emission $\left(F_{M}\right)$. B) Normalized $\Phi_{\text {PSII }}$ values as a function of incubation time for an algae suspension $\left(2.10^{7}\right.$ cells $\left.\mathrm{mL}^{-1}\right)$ incubated with quinones at a concentration of $100 \mu \mathrm{mol} \mathrm{L}{ }^{-1}$.

Figure 5. A) Schematized kinetics of the Electro-Chromic Shift (ECS) as measured in Chlamydomonas reinhardtii algae upon excitation with a supersaturating laser pulse. Three phases can thus be evidenced in pink ("a phase"), blue ("b phase") and green (slow decay phase) that correspond to different enzyme activity (pink: PSII and PSI, blue: $\mathrm{b}_{6} f$, green: ATP synthase). B) Monitoring of the status of ATP synthase for algae suspensions at $2 \times 10^{7}$ cells $\mathrm{mL}^{-1}$ : laser flash-induced ECS kinetics in the presence of various quinones (DQ, 2,6-DMBQ, 2,6-DMBQ, PPBQ; concentration of $100 \mu \mathrm{mol} \mathrm{L}^{-1}$ ) and in the control. Time 0 corresponds to the laser flash.

Figure 6. Representative chronoamperograms from a suspension of Chlamydomonas reinhardtii algae $\left(2 \times 10^{7}\right.$ cells $\left.\mathrm{mL}^{-1}\right)$ under illumination with 2,6-DCBQ, MorphoBQ and DMPPBQ $\left(100 \mu \mathrm{mol} \mathrm{L}{ }^{-1}\right)$.

Figure 7. A) Maximum photocurrents measured for different quinones $\left(100 \mu \mathrm{mol} \mathrm{L}{ }^{-1}\right)$ from a suspension of Chlamydomonas reinhardtii algae $\left(2 \times 10^{7}\right.$ cells $\left.\mathrm{mL}^{-1}\right)$ as a function of the steady state duration. The dashed zone corresponds to the uncertainties of steady state stability due to the low measured photocurrents. B) Maximum stable photocurrents measured for a quinone concentration equal to $\mathrm{CC} 20$, i.e. a quinone concentration range where incubation of quinones prevent $20 \%$ of cells to grow. C) Ratio of the maximum stable photocurrent (for CC20) to $\mathrm{CC} 20$ as a function of $\mathrm{E}^{\circ}\left(\mathrm{QH}_{2} / \mathrm{Q}\right)$ values at $\mathrm{pH} 7$. 


\section{References}

[1] X. G. Zhu, S. P. Long, D. R. Ort, Annu. Rev. Plant Biol. 2010, 61, 235-261.

[2] a) R. E. Blankenship, D. M. Tiede, J. Barber, G. W. Brudvig, G. Fleming, M. Ghirardi, M. R. Gunner, W. Junge, D. M. Kramer, A. Melis, T. A. Moore, C. C. Moser, D. G. Nocera, A. J. Nozik, D. R. Ort, W. W. Parson, R. C. Prince, R. T. Sayre, Science 2011, 332, 805-809; b) K. L. Saar, P. Bombelli, D. J. Lea-Smith, T. Call, E.-M. Aro, T. Mueller, C. J. Howe, T. P. J. Knowles, Nat. Energy 2018, 3, 75-81.

[3] a) M. Rosenbaum, Z. He, L. T. Angenent, Curr. Opin. Biotechnol. 2010, 21, 259-264; b) C. F. Meunier, X.-Y. Yang, J. C. Rooke, B.-L. Su, ChemCatChem 2011, 3, 476-488; c) A. Badura, T. Kothe, W. Schuhmann, M. Roegner, Energy Environ. Sci. 2011, 4, 3263 3274; d) D. P. B. T. B. Strik, R. A. Timmers, M. Helder, K. J. J. Steinbusch, H. V. M. Hamelers, C. J. N. Buisman, Trends Biotechnol. 2011, 29, 41-49; e) R. A. Voloshin, V. D. Kreslavski, S. K. Zharmukhamedov, V. S. Bedbenov, S. Ramakrishna, S. I. Allakhverdiev, Biofuel Res. J. 2015, 2, 227-235; f) N. Sekar, R. P. Ramasamy, J. Photochem. Photobiol. C 2015, 22, 19-33; g) A. J. McCormick, P. Bombelli, R. W. Bradley, R. Thorne, T. Wenzel, C. J. Howe, Energy Environ. Sci. 2015, 8, 1092-1109.

[4] a) J. Tschörtner, B. Lai, J. O. Krömer, Front. Microbiol. 2019, 10, article866; b) L. T. Wey, P. Bombelli, X. L. Chen, J. M. Lawrence, C. M. Rabideau, S. J. L. Rowden, J. Z. Zhang, C. J. Howe, ChemElectroChem 2019, 6, 5375-5386; c) F. Milano, A. Punzi, R. Ragni, M. Trotta, G. M. Farinola, Adv. Funct. Mater. 2019, 29; d) J. Z. Zhang, E. Reisner, Nat. Rev. Chem. 2020, 4, 6-21; e) M. Grattieri, K. Beaver, E. M. Gaffney, F. Y. Dong, S. D. Minteer, Chem. Commun. 2020, 56, 8553-8568.

[5] a) M. Kato, J. Z. Zhang, N. Paul, E. Reisner, Chem. Soc. Rev. 2014, 43, 6485-6497; b) R. Tel-Vered, I. Willner, ChemElectroChem 2014, 1, 1778-1797; c) J. O. Calkins, Y. Umasankar, H. O'Neill, R. P. Ramasamy, Energy Environ. Sci. 2013, 6, 1891-1900; d) M. Rasmussen, A. Shrier, S. D. Minteer, Phys. Chem. Chem. Phys. 2013, 15, $9062-$ 9065; e) M. Rasmussen, S. D. Minteer, Phys. Chem. Chem. Phys. 2014, 16, $17327-$ 17331; f) J. Z. Zhang, P. Bombelli, K. P. Sokol, A. Fantuzzi, A. W. Rutherford, C. J. Howe, E. Reisner, J. Am. Chem. Soc. 2018, 140, 6-9.

[6] a) K. Hasan, Y. Dilgin, S. C. Emek, M. Tavahodi, H.-E. Akerlund, P.-A. Albertsson, L. Gorton, ChemElectroChem 2014, 1, 131-139; b) E. R. Clifford, R. W. Bradley, L. T. Wey, J. M. Lawrence, X. L. Chen, C. J. Howe, J. Z. Zhang, Chem. Sci. 2021, 12, 33283338 . 
S. Izawa, Methods Enzymol. 1980, 69, 413-434.

[8] M. Grattieri, Z. Rhodes, D. P. Hickey, K. Beaver, S. D. Minteer, ACS Catal. 2019, 9 , 867-873.

[9] a) G. Longatte, H.-Y. Fu, O. Buriez, E. Labbe, F.-A. Wollman, C. Amatore, F. Rappaport, M. Guille-Collignon, F. Lemaitre, Biophys. Chem. 2015, 205, 1-8; b) G. Longatte, F. Rappaport, F. A. Wollman, M. Guille-Collignon, F. Lemaitre, Photochem. Photobiol. Sci. 2016, 15, 969-979.

[10] a) H.-Y. Fu, D. Picot, Y. Choquet, G. Longatte, A. Sayegh, J. Delacotte, M. GuilleCollignon, F. Lemaitre, F. Rappaport, F.-A. Wollman, Nat. Commun. 2017, 8; b) G. Longatte, F. Rappaport, F.-A. Wollman, M. Guille-Collignon, F. Lemaitre, Electrochim. Acta 2017, 236, 327-332.

[11] a) G. Longatte, M. Guille-Collignon, F. Lemaitre, ChemPhysChem 2017, 18, 26432650; b) L. Beauzamy, F. Lemaitre, J. Derr, Sustain. Energ. Fuels 2020, 4, 6004-6010.

[12] G. Longatte, A. Sayegh, J. Delacotte, F. Rappaport, F.-A. Wollman, M. GuilleCollignon, F. Lemaitre, Chem. Sci. 2018, 9, 8271-8281.

[13] A. Sayegh, G. Longatte, O. Buriez, F.-A. Wollman, M. Guille-Collignon, E. Labbe, J. Delacotte, F. Lemaitre, Electrochim. Acta 2019, 304, 465-473.

[14] a) A. R. Grossman, S. J. Karpowicz, M. Heinnickel, D. Dewez, B. Hamel, R. Dent, K. K. Niyogi, X. Johnson, J. Alric, F. A. Wollman, H. Y. Li, S. S. Merchant, Photosynth. Res. 2010, 106, 3-17; b) S. S. Merchant, S. E. Prochnik, O. Vallon, E. H. Harris, S. J. Karpowicz, G. B. Witman, A. Terry, A. Salamov, L. K. Fritz-Laylin, L. MarechalDrouard, W. F. Marshall, L. H. Qu, D. R. Nelson, A. A. Sanderfoot, M. H. Spalding, V. V. Kapitonov, Q. H. Ren, P. Ferris, E. Lindquist, H. Shapiro, S. M. Lucas, J. Grimwood, J. Schmutz, P. Cardol, H. Cerutti, G. Chanfreau, C. L. Chen, V. Cognat, M. T. Croft, R. Dent, S. Dutcher, E. Fernandez, H. Fukuzawa, D. Gonzalez-Ballester, D. GonzalezHalphen, A. Hallmann, M. Hanikenne, M. Hippler, W. Inwood, K. Jabbari, M. Kalanon, R. Kuras, P. A. Lefebvre, S. D. Lemaire, A. V. Lobanov, M. Lohr, A. Manuell, I. Meir, L. Mets, M. Mittag, T. Mittelmeier, J. V. Moroney, J. Moseley, C. Napoli, A. M. Nedelcu, K. Niyogi, S. V. Novoselov, I. T. Paulsen, G. Pazour, S. Purton, J. P. Ral, D. M. Riano-Pachon, W. Riekhof, L. Rymarquis, M. Schroda, D. Stern, J. Umen, R. Willows, N. Wilson, S. L. Zimmer, J. Allmer, J. Balk, K. Bisova, C. J. Chen, M. Elias, K. Gendler, C. Hauser, M. R. Lamb, H. Ledford, J. C. Long, J. Minagawa, M. D. Page, J. M. Pan, W. Pootakham, S. Roje, A. Rose, E. Stahlberg, A. M. Terauchi, P. F. Yang, S. Ball, C. Bowler, C. L. Dieckmann, V. N. Gladyshev, P. Green, R. Jorgensen, S. 
Mayfield, B. Mueller-Roeber, S. Rajamani, R. T. Sayre, P. Brokstein, I. Dubchak, D. Goodstein, L. Hornick, Y. W. Huang, J. Jhaveri, Y. G. Luo, D. Martinez, W. C. A. Ngau, B. Otillar, A. Poliakov, A. Porter, L. Szajkowski, G. Werner, K. M. Zhou, I. V. Grigoriev, D. S. Rokhsar, A. R. Grossman, Science 2007, 318, 245-251; c) L. HouilleVernes, F. Rappaport, F.-A. Wollman, J. Alric, X. Johnson, Proc. Natl. Acad. Sci. USA 2011, 108, 20820-20825.

[15] B. Rimbault, D. Esposito, D. Drapier, Y. Choquet, D. Stern, F. A. Wollman, Mol. Gen. Genet. 2000, 264, 486-491.

[16] a) D. Buckley, H. B. Henbest, P. Slade, J. Chem. Soc. 1957, 4891-4900; b) V. K. Tandon, S. Kumar, N. N. Mishra, P. K. Shukla, Eur. J. Med. Chem. 2012, 56, 375-386.

[17] T. Kitagawa, J. Toyoda, K. Nakasuji, H. Yamamoto, I. Murata, Chem. Lett. 1990, 897900 .

[18] S. Zhang, F. J. Song, D. B. Zhao, J. S. You, Chem. Commun. 2013, 49, 4558-4560.

[19] a) B. Genty, J. M. Briantais, N. R. Baker, Biochim. Biophys. Acta 1989, 990, 87-92; b) K. Maxwell, G. N. Johnson, J. Exp. Bot. 2000, 51, 659-668; c) E. H. Murchie, T. Lawson, J. Exp. Bot. 2013, 64, 3983-3998.

[20] a) K. K. Karukstis, S. C. Boegeman, J. A. Fruetel, S. M. Gruber, M. H. Terris, Biochim. Biophys. Acta 1987, 891, 256-264; b) K. K. Karukstis, S. M. Gruber, J. A. Fruetel, S. C. Boegeman, Biochim. Biophys. Acta 1988, 932, 84-90.

[21] a) A. Brunmark, E. Cadenas, Chem. Biol. Interact. 1988, 68, 273-298; b) X. W. Guo, H. Mayr, J. Am. Chem. Soc. 2014, 136, 11499-11512; c) T. J. Monks, R. P. Hanzlik, G. M. Cohen, D. Ross, D. G. Graham, Toxicol. Appl. Pharmacol. 1992, 112, 2-16.

[22] L. Beauzamy, J. Delacotte, B. Bailleul, K. Tanaka, S. Nakanishi, F. A. Wollman, F. Lemaitre, Anal. Chem. 2020, 92, 7532-7539.

[23] P. Mitchell, Nature 1961, 191, 144-\&.

[24] A. Kanazawa, D. M. Kramer, Proc. Natl. Acad. Sci. USA 2002, 99, 12789-12794.

[25] H. T. Witt, Biochim. Biophys. Acta 1979, 505, 355-427.

[26] B. Bailleul, P. Cardol, C. Breyton, G. Finazzi, Photosynth. Res. 2010, 106, 179-189.

[27] P. Joliot, R. Delosme, Biochim. Biophys. Acta 1974, 357, 267-284.

[28] F. Buchert, B. Bailleul, T. Hisabori, Biochim. Biophys. Acta Bioenerg. 2017, 1858, 966974.

[29] P. Joliot, A. Joliot, Biochim. Biophys. Acta Bioenerg. 2008, 1777, 676-683.

[30] a) G. A. Moore, L. Rossi, P. Nicotera, S. Orrenius, P. J. Obrien, Arch. Biochem. Biophys. 1987, 259, 283-295; b) P. J. Obrien, Chem. Biol. Interact. 1991, 80, 1-41; c) L. 
Rossi, G. A. Moore, S. Orrenius, P. J. Obrien, Arch. Biochem. Biophys. 1986, 251, 2535.

[31] C. Preston, C. Critchley, Photosynth. Res. 1988, 16, 187-202.

[32] P. R. Rich, D. S. Bendall, Biochim. Biophys. Acta 1980, 592, 506-518.

[33] V. Petrouleas, B. A. Diner, Biochim. Biophys. Acta 1987, 893, 126-137.

[34] Y. Song, G. R. Buettner, Free Radical Biol. Med. 2010, 49, 919-962.

[35] W. Flaig, Beutelsp.H, H. Riemer, E. Kalke, Justus Liebigs Ann. Chem. 1969, 719, 96111.

[36] K. Ollinger, G. D. Buffinton, L. Ernster, E. Cadenas, Chem. Biol. Interact. 1990, 73, 5376. 